\title{
National Primate Plan
}

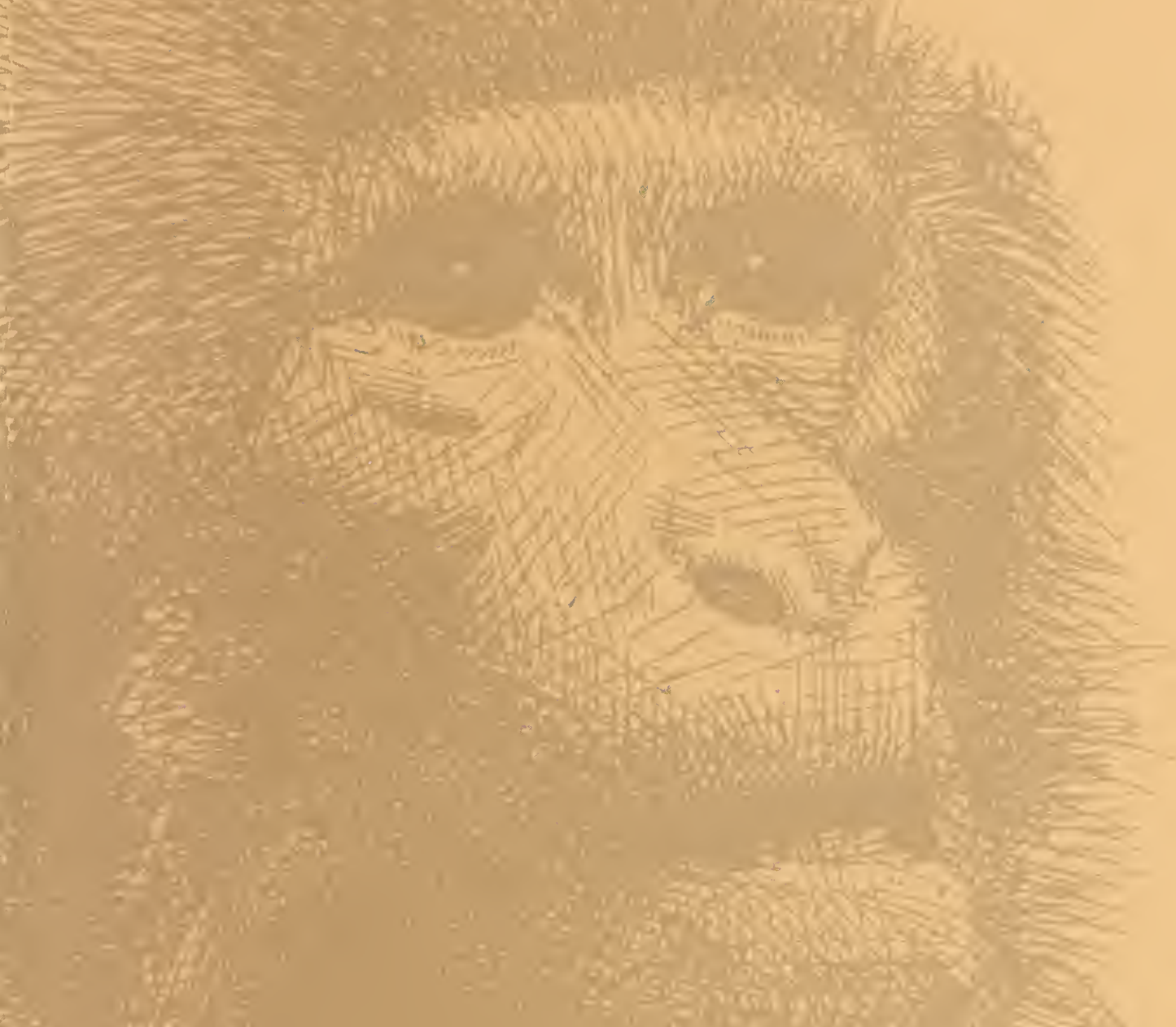


Several species of primates of biomedical importance are listed as Endangered or Threatened under the Endangered Species Act of 1973. Section 7 of the Act directs all Federal agencies, in consultation with the Secretary of Interior, to insure that actions authorized, funded, or carried out by them do not jeopardize the continued existence of listed species, in the United States or in foreign countries. Responsibilities for this consultation have been delegated to the Fish and Wildlife Service, which has published "Interagency Cooperation Regulations" requiring every Federal agency to review its own actions to determine whether they may affect listed species, and to initiate consultation with the director of the service for all activities which may affect listed species.
Accordingly, the National Primate Plan was subjected to the section 7 consultation process. The resulting biological opinion, of the director, Fish and Wildlife Service, states that adoption of the plan as a national policy for the acquisition and use of primates for biomedical purposes is not likely to jeopardize the continued existence of listed species.

The Interagency Primate Steering Committee, and the participating agencies, recognize their obligation to initiate section 7 consultation whenever they contemplate an activity to implement the plan which may affect listed species. 

PREFACE. . . . . . . . . . . . . . . . . . . . . . iii

EXECUTIVE SUMMARY. . . . . . . . . . . . . . . . . . . v v

CHAPTER I - STATEMENT OF THE PROBLEM . . . . . . . . . . . . . 1

A. The Continuation of Many Essential Health Activities

Depends Upon the Use of Nonhuman Primates. . . . . . . . . . 1

B. There Now Exists a Severe and Long-Term Shortage of
Primates . . . . . . . . . . . . . . 4

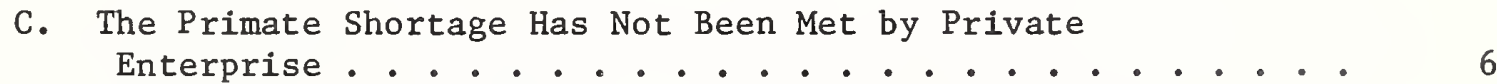

D. Federal Action Is Required to Deal With the Problem . . . . 6

CHAPTER II - ACTIONS TO MEET NATIONAL HEALTH NEEDS . . . . . . . . . 9

A. Introduction. . . . . . . . . . . . . . . . . 9 9

B. Ensuring the Most Effective Use of Primates . . . . . . . . 12

C. Production of Primates in the United States . . . . . . . . 16

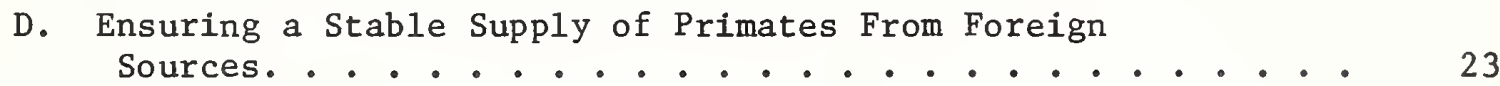

CHAPTER III - CONTINGENCY PLAN FOR ALLOCATION OF PRIMATES. • . • . . . 29

CHAPTER IV - INFORMATION REQUIREMENTS AND NATIONAL PRIMATE
PROGRAM MONITORING. . . . . . . . . . . . . . . 31

CHAPTER V - ACTION IMPLEMENTATION. . . . . . . . . . . . . . 35

A. Current Status. . . . . . . . . . . . . . . 35

B. Future Requirements . . . . . . . . . . . . . 37

APPENDIXES

$\begin{array}{ll}\text { Appendix } & \text { Page }\end{array}$

A PRESENTATIONS OF PRIMATE REQUIREMENTS. . . . . . . 41

B DISCUSSION OF MAJOR PRIMATE SPECIES. . . . . . . . . . 51

C INTERAGENCY PRIMATE STEERING COMMITTEE (Membership). • • 69

D U.S. DOMESTIC PRODUCTION OF NONHUMAN PRIMATES

SUPPORTED BY FEDERAL GOVERNMENT BY SPONSOR AND

SPECIES. . . . . . . . . . . . . . . 73

E SUMMARY OF INTERAGENCY PRIMATE STEERING COMMITTEE

RESPONSIBILITIES . . . . . . . . . . . 77 
The director of the National Institutes of Health, in October 1974, established a steering committee to develop a unified approach to assure both short - and long-term supplies of nonhuman primates for biomedical research activities. This action was taken in response to the shortages of a number of primate species vital to biomedical research activities. The committee was later expanded by the Assistant Secretary for Health, Department of Health, Education, and Welfare (DHEW) to include other DHEW organizations as well as other agencies of the Federal Government.

Through the efforts of this committee, major steps have been taken to ensure adequate and continuing supplies of primates for biomedical research and other essential health activities. These include:

* expansion of domestic production of primates;

* development of international programs for the production and conservation of several species of primates; and

* action to assure the most effective use of available primates.

The National Primate Plan, prepared by the committee, is a combination of program activities that have been in operation for some time and others that remain to be initiated. As the plan is implemented, it will result in a National Primate Program with operational functions for each component activity carried out by the agency most concerned. The committee will continue to be responsible for coordinating and representing the combined interest of government agencies in the supply, utilization, and conservation of nonhuman primates. It will also be responsible for monitoring and periodic evaluation of activities in order to maintain a comprehensive, unified program to assure a continuous supply of nonhuman primates to meet essential health and other scientific needs of the nation.

The membership of the Interagency Primate Steering Committee includes representatives from the National Science Foundation, the Department of Defense, the Environmental Protection Agency, the Veterans Administration, and five DHEW components: the Alcoho1, Drug Abuse, and Mental Health Administration; the Center for Disease Control; the Food and Drug Administration; the Office of International Health; and the National Institutes of Health, the lead agency. Representatives of other agencies participate in the work of the committee on an ad hoc basis.

Communications should be addressed to:

Executive Director

Interagency Primate Steering Committee

NIH Building 31, Room 4B30

Bethesda, Maryland 20014 
Statement of the Problem

A severe and long-term shortage of nonhuman primates threatens the continuation of many essential health activities. This shortage includes the rhesus monkey and other species needed for health and other scientific purposes. The Interagency Primate Steering Committee (IPSC), representing the combined interests of the Federal Government in the supply, use, and conservation of nonhuman primates, has developed this National Primate Plan which, when implemented, will ensure adequate supplies of primates to meet those needs of importance to the health and welfare of the American people.

\section{Actions to Meet National Health Needs}

Many programs have already been initiated to increase the availability of nonhuman primates by organizations conducting and sponsoring health activities. The goal of this plan is to structure, balance, and extend these actions in a coordinated and efficient manner so that the requirements of all essential health activities can be met now and in the future.

After reviewing these programs in light of the total requirement and availability of nonhuman primates, three complementary thrusts of action are recommended:

I. Action must be taken to ensure the most effective use of primates (page 12). The shortage of primates necessitates their use in the most effective manner and only when essential. Every use or proposed use of primates must be critically assessed to minimize the number of primates required and at the same time maximize the benefit of their use. It is, therefore, recommended that:

* sponsors (page 12), as part of their project review mechanisms, critically assess each proposed use of nonhuman primates according to established criteria;

* a procedure be established allowing Federal agencies to coordinate with the IPSC during the development of regulations which either require that primates be used or restrict their availability (page 13);

* all sponsors require recycling and the multiple use of primates (page 14); and 
* The National Institutes of Health assume responsibility for developing and operating a primate users' service on a national scale (page 14 ).

II. Action must be taken to sufficiently expand domestic primate production to ensure a continuous, stable, and long-term supply of primates required by essential health activities (page 16). Reduction in supplies of imported primates have resulted in some major governmental efforts to develop domestic primate production colonies. These colonies, together with the numerous small breeding colonies operated by research institutions to meet their own needs, are insufficient. It is, therefore, recommended that:

* a nationally coordinated program of domestic primate production be established (page 18).

It is not practical to meet all requirements for all species from domestic breeding. In the case of the rhesus monkey (Macaca mulatta), however, the domestic production program must provide for practically all of the nation's needs. Production of the cynomolgus monkey (M. fascicularis) must be increased also, in order to meet an increasing proportion of estimated needs. Each primate species needed in essential health activities requires a minimum of two general-purpose production colonies. It is, therefore, recommended that:

* in addition to existing colonies, a series of generalpurpose domestic production colonies and a large number of special-purpose colonies (dictated by the needs of a particular research project or program), with limited production goals but with, possibly, less-commonly used species, be designed and established according to the criteria presented on page 19 of this plan.

* the production of rhesus monkeys in general-purpose colonies be expanded to provide 9,000 animals per year, and that the general-purpose production of cynomolgus monkeys be supported at a level to pro duce at least 3,000 annually.

* additional colonies should include, as a minimum, the following:

Species

Additional Colonies Required

Saguinus mystax Callithrix jacchus 2 Cercopithecus aethiops Aotus trivirgatus Sanguinus oedipus

\section{Minimum Annual Output Level Per Colony}

Refer to Page

57 to 58

59 to 60

65

61

57 to 58 
Since future biomedical needs may require species of primates not currently used in sufficient numbers to warrant generalpurpose production, it is recommended that:

* the need for each species of primate be continually reevaluated with domestic production programs adjusted as required; that

* existing special breeding programs be identified and recognized as important resources; and that

* additional special breeding colonies be encouraged to meet the general requirement for more information on a wider variety of species (page 21).

In order to ensure the development of a balanced, nationally coordinated program, sponsors must coordinate their activities and exchange information. Therefore, it is recommended that:

* the IPSC review all breeding proposals and facilitate the exchange of information between and among sponsors of such programs.

III. Action must be taken to ensure a stable supply and the long-term availability of primates from their countries of origin (page 23).

The United States is largely dependent on foreign sources for its primate supplies. The availability of primates for export from their native countries is fundamentally dependent upon the official policies and practices of the governments of those countries. In order to lend stability and constancy to these primate supplies, it is recommended that:

* appropriate international arrangements be established (page 23); and that

* government-to-government arrangements be made when commercial supply channels are unable to supply our needs (page 23). 
The availability of primates for export from their native countries is dependent upon the governments of those countries, and they require reliable information on primate population. It is recommended that:
* appropriate international assistance be offered to interested source countries in performing surveys of primate populatons and in the development of monitoring/ management services for such populations (page 24).

It is the primary responsibility of each organization sponsoring health activities to ensure that adequate primate supplies are available for its own areas of concern. Therefore, sponsors are expected to supplement existing programs or develop new programs, as their needs may dictate, within each of these recommended thrusts of action. The IPSC is charged with the responsibility of coordinating these efforts and assisting sponsors from both the public and private sectors in the development of such programs.

\section{Contingency Plan Allocation of Primates}

In view of the uncertainties of current and future primate supplies, it is possible there will be insufficient numbers of one or more species to meet the minimum overall health needs of the country. It is, therefore, recommended that:

* a contingency plan for the allocation of available primates be established (page 29).

As a general policy, organizations providing funds for primate production will be responsible for allocation of those animals. In the event overall supplies are insufficient to meet critical health needs, it is recommended that:

* the distribution of primates be handled through interagency consultation and allocated in priority order. This order is:

(1) to fulfill requirements of Federal law and regulations;

(2) for breeding colonies, and

(3) for other biomedical research and development purposes (page 29). 
The IPSC should facilitate the consultative process and provide for participation of nongovernmental institutions. In the event the consultations do not produce agreement, it is recommended that:

* the IPSC present the matter to the Assistant Secretary for Health, Department of Health, Education, and Welfare (page 30).

\section{Information Requirements and Program Monitoring}

An integral component of a National Primate Program is the development of a means to assess current and future requirements for primates and the availability of sources of supplies to meet these requirements. In order to accomplish this, it is recommended that:

* each sponsor regularly assess its own needs for primates; and that

* the IPSC assume responsibility for national assessment of overall needs and availability (page 31 ).

Accurate and comprehensive assessment depends upon accurate and comprehensive information. Accordingly, it is recommended that:

* sponsors develop a capability to define primate requirements for all projects under their sponsorship (page 32);

* the IPSC determine the availability of primates from foreign sources (page 30); and that

* each sponsor periodically inform the IPSC of the status of the domestic primate production activities (page 33 ).

In addition to information describing the immediate and short-range situations, information which provides an overall perspective of the supply/demand picture must be developed. It is, therefore, recommended that:

* the IPSC, through the analysis of usage trends, research developments, and other indices develop an overall perspective of the nation's long-term needs for primates (page 33).

It is through the development of this national perspective, which is sensitive to national health needs, that the progress of the National 
Primate Program can be monitored and modified as necessary. The IPSC, representing the combined interests of sponsors, should provide for a forum where additional plans can be developed effecting positive change within the primate usage system. 


\title{
CHAPTER I
}

STATEMENT OF THE PROBLEM

\begin{abstract}
A severe and long-term shortage of nonhuman primates threatens the continuation of many essential health activities. This shortage includes the rhesus monkey and other primate species needed for health and other scientific purposes. 1 The primate shortage has not been met by private enterprise. Federal action is required to deal with the problem.
\end{abstract}

A. The Continuation of Many Essential Health Activities Depends Upon the Use of Nonhuman Primates.

In 1977, an estimated total of 34,000 nonhuman primates ${ }^{2}$ often referred to simply as "primates" were used by the United States biomedical community in a wide variety of health-related activities. The use of these animals is so critical to some of these activities that specific laws and regulations ${ }^{3}$ dictate their use. In others, good scientific practice developed through many years of experience requires their use with force equivalent of that of law.4,5 The essentiality of their use rests in large extent upon the relation of the nonhuman primate to

INonhuman primates imported into the United States have, in the past, been used primarily to meet many health needs, such as the production and testing of vaccines, safety testing of drugs, and biomedical research. They are also essential for other closely related bioscientific purposes, such as behavioral research and the development of basic information regarding the biology of primates, per se. Because of the interdependence of these activities and their importance to health programs, this report is intended to reflect requirements for all health and bioscientific purposes. For simplicity, the term "health" or "biomedical" will be used inclusively to incorporate all of these various scientific uses.

${ }^{2}$ See appendix A.

${ }^{3}$ Title 21 CFR 600-680 (Food \& Drugs; Biologics).

${ }^{4}$ FDA Introduction to Total Drug Quality, DHEW Pub. No. (FDA) 74-3006, Washington, D.C., 1974.

5 Food and Drug Administration, Contraception, Estrogens, Progestogens: A New FDA Policy on Animal Studies, FDA Papers, vol. 3, Washington, D.C., 1969 . 
the human primate--man. These animals are man's closest relatives in the animal kingdom and are therefore indispensable allies in the effort to understand and control problems of human health. Without their use, such essential activities as the production of poliomyelitis vaccine would be seriously curtailed. The use of primates as experimental models has been required to increase our knowledge and understanding of many human disease processes including infectious diseases such as hepatitis; neoplastic diseàses such as cancer; diseases of organ systems, especially within the cariovascular system; and the parasitic diseases such as malaria. New knowledge yet to be discovered can be expected to depend upon the availability of these animals. The actual application of the fruits of research to man, also, depends to a large extent on nonhuman primates. Without preliminary testing in these animals, the risks may be too great to apply theoretical knowledge directly to man himself.

The 34,000 additional nonhuman primates needed in 1977 comprise some 35 different species, each possessing specific characteristics of particular value in meeting national health needs. The relative importance of each of these species is continually changing. Some notable influences causing this change are: (1) an acceleration in the state of the art of biomedical research resulting in an increasing need for a larger number and wider variety of animal models more closely related to man; (2) the identification of characteristics not previously recognized, peculiar to a species, which makes them particularly desirable as models of human disease, and (3) the substitution for species now in short supply. A discussion of the major species in relation to these influences and other factors can be found in appendix B. A summary of primate uses is presented here in table 1. 


\section{Table 1}

\section{Major Uses of Essential Primate Species Required by U.S. Biomedical Activities *}

\begin{tabular}{|c|c|c|}
\hline Species & $\begin{array}{l}\text { Number } \\
\text { Required } \\
\text { Annually }\end{array}$ & Major Uses \\
\hline $\begin{array}{l}\text { Macaca mulatta } \\
\text { (rhesus monkey) }\end{array}$ & 14,000 & $\begin{array}{l}\text { General purpose, production and } \\
\text { testing of biological products, vaccines } \\
\text { such as poliomyelitis }\end{array}$ \\
\hline $\begin{array}{l}\text { M. fascicularis } \\
\text { (cynomolgus) }\end{array}$ & 6,000 & General purpose, drug safety testing \\
\hline Other macaque & 1,000 & $\begin{array}{l}\text { Neuroscience, behavioral studies, many } \\
\text { other research areas }\end{array}$ \\
\hline $\begin{array}{l}\text { Saguinus spp. } \\
\text { (marmosets or tamarins) }\end{array}$ & 2,200 & $\begin{array}{l}\text { Hepatitis research, viral oncology, } \\
\text { immunology, reproductive physiology }\end{array}$ \\
\hline $\begin{array}{l}\text { Callithrix jacchus } \\
\text { (common marmoset) }\end{array}$ & 200 & $\begin{array}{l}\text { General research, reproductive physiology, } \\
\text { teratology, drug safety testing }\end{array}$ \\
\hline $\begin{array}{l}\text { Aotus trivirgatus } \\
\text { (owl monkey) }\end{array}$ & 1,500 & $\begin{array}{l}\text { Malaria chemotherapy, immunology } \\
\text { studies, vision research }\end{array}$ \\
\hline $\begin{array}{l}\text { Pan troglodytes } \\
\text { (common chimpanzee) }\end{array}$ & 180 & Hepatitis research, psychobiology \\
\hline $\begin{array}{l}\text { Hylobates lar } \\
\text { (white-handed gibbon) }\end{array}$ & 100 & $\begin{array}{l}\text { Cancer viruses, hepatitis B research, } \\
\text { behavioral studies }\end{array}$ \\
\hline $\begin{array}{l}\text { Papio spp. } \\
\text { (baboons) }\end{array}$ & 1,300 & $\begin{array}{l}\text { General purpose, experimental surgery, } \\
\text { reproductive physiology research }\end{array}$ \\
\hline $\begin{array}{l}\text { Cercopithecus aethiops } \\
\text { (African green monkey) }\end{array}$ & 2,100 & $\begin{array}{l}\text { Production of biological material, } \\
\text { toxicology testing }\end{array}$ \\
\hline $\begin{array}{l}\text { Saimiri sciureus } \\
\text { (squirrel monkey) }\end{array}$ & 4,500 & $\begin{array}{l}\text { General research, drug testing, nutrition, } \\
\text { cardiovascular research }\end{array}$ \\
\hline Other primate species & 1,000 & $\begin{array}{l}\text { Biomedical research in general, many } \\
\text { specific applications }\end{array}$ \\
\hline
\end{tabular}

*This table consists of agency estimates based on historical usage and availability in 1977. Future usage patterns will be affected by availability and/or the determination that certain species are better for particular needs. 
B. There Now Exists a Severe and Long-Term Shortage of Primates.

In recent years the destruction of primate habitats and embargos on the exportation of primates from countries of origin have decreased the supply of these animals at an alarming and accelerated rate. The rapid expansion of human populations and economic development in many tropical countries often leads to the destruction of forests for lumber or agriculture. This, in turn, has drastically reduced some indigenous primate populations. Primates come primarily from developing nations, where there has been an increasing concern about the depletion of natural resources. Many of these countries have taken steps to conserve their fauna and flora by imposing restrictions on exportation. An important example is the Indian government controls on export of rhesus monkeys (Macaca mulatta).

Historically, the rhesus has been the most important and widely used primate in health programs. In 1973, the Government of India reduced the annual exportation of this species from a previous worldwide total of 50,000 animals to 30,000, and a year later reduced this number to 20,000. Importation by the United States during this time was reduced by 50 percent - from 24,000 animals annually to the 1977 level of about 12,000 animals. Effective April 1, 1978, the Government of India banned all further exports of primates.

Also essential in biomedical research are certain New World primates. These include several tamarin species (Saguinus spp.), the common marmoset, (Callithrix jacchus), squirrel monkeys (Saimiri sciureus), and owl monkeys (Aotus trivirgatus). Export restrictions imposed by Brazil, Colombia, and Peru have made it very difficult to obtain these animals. In 1972, some 6,000 squirrel monkeys from the Amazon basin were imported into the United States for research purposes at a price of $\$ 30$ each. Currently a subspecies from a different geographic area is available at a price of $\$ 175$ each. Certain marmoset species, urgently needed in hepatitis and cancer research, and the owl monkey, for malaria and vision research, are virtually impossible to obtain commercially.

In November 1976, international action was taken placing all nonhuman primates in either appendix I or II of the Convention on International Trade in Endangered Species. In practical terms, this means that both exporting and importing countries are required to approve international shipments of primates, and, as a minimum requirement, the exporting country must, in every instance, issue a certificate that shipment of the animals will not be detrimental to the survival of the species in the wild. The purpose of this control is commendable, and the procedure is necessary for species that are truly endangered. It could, however, cause uncertainties and unnecessary delays in procurement, even of species that are relatively abundant.

An assessment of the availability of the major primate species is presented in table 2. A more comprehensive discussion of the status of foreign supplies is presented in appendix B. 
Table 2

Present Availability of Wild-caught Primates

1978

\begin{tabular}{|c|c|c|}
\hline Species & $\begin{array}{l}\text { Location of } \\
\text { Indigenous } \\
\text { Populations }\end{array}$ & Availability Assessment ${ }^{\star}$ \\
\hline $\begin{array}{l}\text { Macaca mulatta } \\
\text { (rhesus monkey) }\end{array}$ & $\begin{array}{l}\text { India and } \\
\text { surrounding } \\
\text { countries }\end{array}$ & Continued availability questionable \\
\hline
\end{tabular}

\section{M. fascicularis \\ (cynomolgus)}

Other macaques

Saguinus spp.

(tamarins)

Callithrix jacchus
(common marmoset)

Aotus trivirgatus

(owl monkey)

Pan troglodytes

(common chimp)

Hylobates spp.

(gibbons)

\section{Papio spp.}

(baboons)

Cercopithecus aethiops

(African green monkey)

Saimiri sciureus

(squirrel monkey)
Southeast Asia,

Indonesia,

Philippines

Asia

South America

Brazil

Central and

South America

West Africa

Southeast Asia

Sub-Sahara Africa

Africa

Central and

South America
Commercially available in sufficient numbers to satisfy current demand

Supplies extremely limited or nonexistent

Commercial trade prohibited by most South American countries; small numbers available through special international arrangements

Continued availability questionable

Commercially available in limited numbers

Commercial trade prohibited; threatened species

Commercial trade prohibited; endangered species

Commercially available in sufficient numbers to satisfy current demand

Commercially available in sufficient numbers to satisfy current demand

Commercially available; subspecies in greatest demand not commercially available

Generally supplies are limited; varies according to species

Other

\footnotetext{
"The Convention on International Trade in Endangered Species of Wild Fauna and Flora lists all nonhuman primates either in Appendix I (species threatened with extinction) or in Appendix II (species that may become threatened and for which regulation of trade is, therefore, necessary.
} 
C. The Primate Shortage Has Not Been Met by Private Enterprise.

In the past, commercial organizations have dealt almost exclusively with the importation of primates and very limitedly with their production through breeding. Because of the diminishing number of animals available for importation, the primate import business may not be commercially viable within a few years. Only now are some breeding programs being established in the private sector through contractual arrangements with the United States Government to meet the specific needs of various Federal agencies. Among these contractors, two have also entered the primate import business by purchasing two of the major importers of old World primates, an indication that organizations seeking a balance to maintain viability must look at both importation and domestic breeding as sources of supply.

The involvement of private enterprise in general primate production as an independent commercial venture is unlikely at this time because of many unfavorable circumstances. Current experience with rhesus monkeys indicates that at least 10 years of operation would be required before sufficient income is earned to offset the costs of starting a breeding program. Initial investments, exclusive of land, range from $\$ 1,150$ to $\$ 2,400$ per breeding animal depending upon the type of facility. Three to 5 years are required before any return can be expected from the sale of animals. Even in the face of continual reductions and undependable supplies of imported animals and a relatively stable demand, this type of commercial venture would be high risk with a small return on investment. Assuming that sufficient capital were available for such operations, few organizations have personnel with the necessary expertise in primate production to operate such facilities. There is no evidence that the private sector will enter this market under the current circumstances.

\section{Federal Action Is Required to Deal With the Problem.}

Nonhuman primates have been shown to be essential to the health status of the people of the United States. Continuation of many ongoing and new activities contributing to the improvement of man's health is threatened by inadequate and erratic supplies of these resources. In the absence of the private sector's involvement, immediate Federal action is required. Federal action designed

* to ensure the most effective use of our current supplies of primates; 
* to develop domestic capability for the production of primates necessary to protect our essential health activities; and

* to ensure a stable supply and the long-term availability of primates from their countries of origin

is necessary in the national interest in order to protect and improve the health of our people. Only the Federal Government can plan and coordinate the required domestic and international facets of a balanced program to deal with this problem effectively and efficiently. 

CHAPTER II

ACTIONS TO MEET NATIONAL HEALTH NEEDS

\section{A. Introduction}

No single organization is charged with the functions necessary to meet national health needs; rather, many interdependent organizations, ranging from governmental agencies through the commercial sector to nonprofit and academic institutions, have assumed different responsibilities. For the discussions that follow, "sponsoring" organizations are considered to be those organizations assuming oversight and/or directional responsibilities (by supplying funds) for the conduct of activities. It is this group that must assess the requirements and ensure a supply of nonhuman primates to meet those health needs within its area of purview. The term "sponsors" is used to identify this set of organizations. The term "performers" is used to identify those organizations actually conducting an activity using primates, regardless of the sponsorship. Some institutions may be both sponsors and performers. This is especially true of academic institutions which, together with various professional societies and trade associations, also have considerable potential for engendering widespread acceptance of this plan and for its effective implementation within the scientific community.

The various sponsors, recognizing their responsibility in this matter, are already actively involved in varying degrees. The goal of this plan is to structure and balance these actions in a coordinated manner so that a comprehensive program can be developed to efficiently meet all needs. A program developed at the national level can:

* address the critical needs of all health activities for primates;

* develop balanced supply programs independent of a single unreliable source of primate supplies;

* employ the talents of private enterprise in developing and maintaining sources of primate supplies;

* coordinate the actions of sponsors and establish cooperative programs to minimize duplicate effort; 
* minimize competition between organizations for the limited supplies of nonhuman primates; and

* reduce direct governmental control, operation, and funding of primate supply programs.

A balanced program of recommended action according to the major thrusts identified in section $D$ of chapter $I$ is outlined below. These recommendations are based on a series of basic assumptions:

* Ultimately, the Federal Government is responsible for ensuring adequate primate supplies to meet those needs of importance to the health and welfare of the American people. In most cases, however, the primary responsibility would best rest with each sponsor to ensure that there are adequate supplies for its own area of concern.

* The design of Federal action must supplement and stimulate rather than supplant private enterprise.

* The requirements for primates outlined in table 3 are assumed to relfect the annual requirements essential to our national health needs as determined by each sponsor indentified within this table. A discussion of these numbers and other supporting data is presented in appendix $A$. 
Table 3

Estimated Annual Requirements for Nonhuman Primates by Sponsor and Species *

\begin{tabular}{|c|c|c|c|c|c|c|c|c|c|c|c|c|c|}
\hline Sponsor & 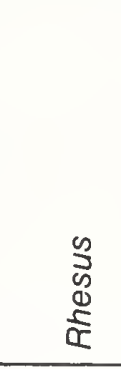 & 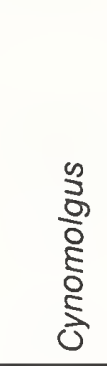 & 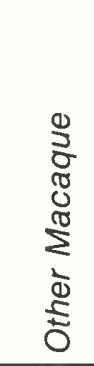 & 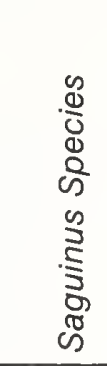 & 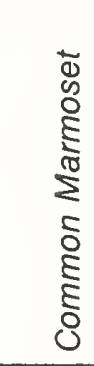 & $\begin{array}{l}\frac{\partial}{d} \\
\frac{1}{5} \\
\frac{1}{\Sigma} \\
\frac{j}{3}\end{array}$ & 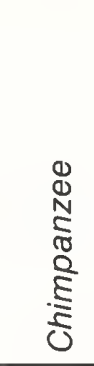 & $\begin{array}{l}5 \\
0 \\
0 \\
0\end{array}$ & $\begin{array}{l}\delta \\
\delta \\
\varnothing \\
\mathbb{0} \\
0\end{array}$ & 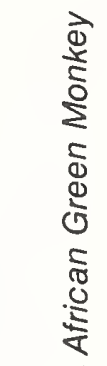 & 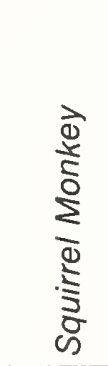 & $\stackrel{\bar{\Phi}}{\stackrel{1}{\Xi}}$ & $\underset{\stackrel{D}{0}}{\stackrel{D}{\circ}}$ \\
\hline \multicolumn{14}{|c|}{$\begin{array}{l}\text { Federal Government } \\
\text { DHEW }\end{array}$} \\
\hline ADAMHA & 150 & 80 & 110 & & & & 5 & & 20 & 5 & 150 & 80 & 600 \\
\hline CDC & 360 & & & 60 & & 90 & 10 & & & 15 & 10 & & 545 \\
\hline FDA & 2280 & 305 & & 300 & & 50 & 25 & & 10 & 50 & 60 & & 3080 \\
\hline \multicolumn{14}{|l|}{$\mathrm{NIH}$} \\
\hline Extramural & 3500 & 2400 & 600 & 700 & 150 & 660 & 100 & 100 & 500 & 600 & 1420 & 700 & 11430 \\
\hline Intramural & 700 & 70 & 15 & 400 & & 35 & & & 20 & 50 & 20 & 45 & 1355 \\
\hline \multicolumn{14}{|l|}{ DoD } \\
\hline Air Force & 550 & 50 & 25 & & & & 6 & & 95 & 25 & 30 & & 781 \\
\hline Army & 800 & 1050 & & & & 100 & & & 80 & & 150 & & 2180 \\
\hline Navy & 150 & 100 & 25 & & & & & & 150 & 50 & 200 & & 675 \\
\hline Other & 180 & 380 & & & & & & & & & & & 560 \\
\hline EPA & 165 & 50 & 25 & & & & & & 60 & 15 & 450 & 5 & 770 \\
\hline ERDA & 20 & 40 & & & & & & & & & 50 & & 110 \\
\hline NASA & 40 & 60 & 50 & & & & & & 25 & & 100 & & 275 \\
\hline NSF & 125 & 20 & 35 & & & & 2 & & 2 & & 10 & 60 & 254 \\
\hline VA & 505 & 30 & 85 & & 20 & 30 & 2 & & 90 & 45 & 55 & & 862 \\
\hline Other Agencies & & & & & & & & & & & & & \\
\hline \multicolumn{14}{|l|}{ Industry } \\
\hline $\begin{array}{l}\text { Pharmaceutical/ } \\
\text { Biological }\end{array}$ & 4300 & 1000 & & 700 & & 500 & 20 & & 100 & 1200 & 1500 & 100 & \\
\hline Other & & & & & & & & & & & & & 9420 \\
\hline Other** & 190 & 370 & 25 & 30 & & & 10 & & 130 & 20 & 240 & & 1015 \\
\hline Total & 14015 & 6005 & 995 & 2190 & 170 & 1465 & 180 & 100 & 1282 & 2075 & 4445 & 990 & 33912 \\
\hline
\end{tabular}

'Based on 1977 data

" Other includes requirements of activities funded by state and local governments, foundations and academic institutions. 


\section{B. Ensuring the Most Effective Use of Primates}

Nonhuman primates must be used effectively and only when essential. The decreasing availability and the increasing cost of primates have caused a reduction in primate use within the last decade. Although economics will continue to affect primate usage, the decision that a primate is essential to use must finally be based upon sound scientific reasoning. Careful assessment of all uses of primates if required, especially when it is proposed they be used in new projects.

It is recommended that actions on all levels be taken to ensure the most effective use of primates. This would include the support of studies to determine which species are best for a given purpose.

Criteria for preparing and reviewing research proposals using nonhuman primates have been prepared by the Interagency Primate Steering Committee (IPSC). 1 The criteria are intended both as a conservation measure for minimizing use of primates and for getting the most benefit from those that must be used. This set of criteria has been distributed throughout the biomedical community where it has been favorably received. Federal agencies sponsoring primate research, with representatives in the committee, are in varying stages of formally incorporating this set of criteria into their management procedures.

These criteria are:

* That the research proposed can be done best with primates; i.e., that no other known system or other kind of animals could produce comparable results.

* That the species of primate proposed is the most appropriate and that some other more plentiful species would not be adequate.

* That the number of primates proposed is the minimum that will produce acceptable scientific results.

* That the primates will not be sacrificed during or at the end of the study except in those cases requiring termination as part of the investigation.

* That, if sacrifice is deemed necessary, positive action will be taken to share body material when feasible.

It is recommended that the formal implementation of this set of criteria be continued, strengthened, and enforced within each sponsor's project review mechanisms. The design of these review procedures should be submitted to the IPSC for advice and comment.

TMembership listed in appendix $C$. 
Clearly, the advancement in basic research and gains in scientific knowledge that have resulted from the use of primates in the past have been in the national interest, and it will also serve that interest to continue to support these kinds of studies. Therefore, considerations should be given to the use of primates for research that cannot always be clearly justified in immediately practical terms, and for studies to determine which species are best for a given purpose.

The assessment of the protocols of research projects and other proposals specifying the use of nonhuman primates is the responsibility of each sponsor within whose purview such projects and proposals fall. Specifications for primate use or restrictions on their availability are also developed by sponsors and other Federal agencies as a result of their regulatory authority. An assessment is necessary of the impact of such regulations on overall national primate needs. The purpose is not to reassess existing requirements but rather to provide an early warning system of impact and a coordinating device in relation to any new requirements and restrictions. For example, if a given agency intends to establish standards for premarket product testing which requires the use of primates, it is essential that it be aware of the availability of these animals and of repercussions such regulation might have on other critical health activities involving primates.

It is recommended that any proposed guideline, standard, or regulation developed by a Federal agency which either requires that primates be used or restricts their availability be submitted to the IPSC to assess the potential impact on the overall national primate supply. In addition, a coordinating procedure should be established to facilitate interaction with the IPSC at the earliest possible stages of such a regulatory development process.

The need for nonhuman primates in activities of a recurring or production nature such as: biologics production, testing, and reference diagnosis was generally identified when these animals were relatively abundant, cost effective, and of unique value for these purposes. Current circumstances make it advisable to reexamine these benefits. Primates are now less plentiful; they are also expensive. Advances in scientific knowledge have made it possible to minimize the number of primates required for these purposes, and continued research may provide methods for further reductions.

It is recommended that sponsors and performers reexamine their need for primates in recurring and production activities, ensuring that there is no acceptable alternative to their use and, where necessary, place increased emphasis on the development of new techniques and procedures in order to further reduce this need. 
Nonhuman primates required for research normally become the subject of a single project or several projects for a defined length of time at the end of which they may become available for other purposes. Central registries of individual primates have been established at a number of institutions and this will enhance their capability to make the best use of the animals on a continuing basis. Many other performers have developed informal systems within their own institutions which facilitate the reuse of these animals when they are no longer required within a specific project. There are also special needs for primates recognized that are well served by the utilization of recycled animals, e.g., for studies requiring aging and aged primates.

It is recommended that insofar as possible, all sponsors require humane and scientifically compatible recycling and multiple use of primates.

This multiple use and recycling is not difficult to accomplish within an institution, especially those heavily engaged in primate research. However, facilitating appropriate multiple use and reuse between institutions is a much more complicated matter, even though the problem basically is one of communications. The Committee on Conservation of Nonhuman Primates, Institute of Laboratory Anima1 Resources of the National Academy of Sciences, has recommended the establishment and operation of a centralized users' service as a move toward maximum use of current primate supplies. They propose a system that "would not only provide rapid information on available animals, or conversely, the need for specific animals, but also facilitate the exchange of biological materials derived from primates." 2 The need for such a users' service has been endorsed by various scientific bodies concerned with primate research.

It is recommended that the National Institutes of Health (NIH), as the lead agency for the IPSC, assume responsibility for developing and operating a users' service on a national scale.

${ }^{2}$ Nonhuman Primates - Usage and Availability for Biomedical Programs, DHEW Publication No. (NIH) 76-892, Washington, D.C. 1975, p.6. 
This service is intended for situations where a performer or sponsor is unable to reutilize animals within its own programs. It is anticipated that the users' service will make it possible for most primates that are no longer needed by one scientist to be readily acquired by another. However, there will be occasions when such matching of offers with needs will not produce immediate results. In other words, it can be anticipated that animals may no longer be required within an institution but would be of potential value to other performers. This institution usually is not prepared to continue to bear the cost of keeping animals. Rather than allow the destruction of rare and valuable animals in such circumstances, they should be donated without restriction to the users' service, which would provide for the financing of their care pending reassignment.

Scientific studies frequently depend upon large numbers of samples to be of optimum research value. The collection of such samples of primate tissues and skeletal material is an expensive and time-consuming process, generally beyond the scope of individual researchers. The development of central repositories of such samples would not only be consistent with the concept of multiple use and ensure the most effective use of primates that might otherwise be lost, but also would greatly facilitate and encourage these types of research endeavors.

It is recommended that sponsors consider the development of central repositories of primate tissues and skeletal material, to be made available to the general research community as appropriate. 
A continuing stable supply of nonhuman primates is necessary for the conduct of essential health activities. Foreign supply sources have proven to be unstable and sometimes discontinuous. Current levels of domestic primate production are insufficient; additional production is necessary to meet essent`ial needs.

It is recommended that the current domestic primate production be sufficiently expanded to ensure a continuous, stable, and long-term supply of primates required by essential health activities.

Only through domestic primate production can the continuation of essential health activities be ensured, in that:

* it provides the greatest degree of stability and accessibility;

* it provides a means to assure continuation of a threatened resource;

* it reduces dependency on a single or limited number of supply sources;

* it contributes to international primate conservation;

* it is the only mechanism that can supply primates for special needs, such as intrauterine fetal research;

* it develops the necessary technology and experience in primate production needed for the future; and

* it provides for the selective breeding of biomedically defined animals of selected genetic backgrounds required for certain research. 
Reductions in the supplies of imported primates have resulted in some major governmental efforts to develop domestic primate production colonies. The Public Health Service (PHS), having prime responsibility for conduct of health activities, initiated actions to secure continuing supply of research primates.

* The NIH Division of Research Resources (DRR), since 1973, has funded contracts with five institutions for primate production programs which ultimately are to become self-sufficient without Federal support.

* The seven Regional Primate Research Centers, in 1973, adoptéd a goal to become self-sufficient in meeting their own primate needs. They are currently able to meet about 50 percent of their needs. The Regional Primate Research Centers receive their core support from DRR.

* The NIH Division of Research Services, since 1973, has funded three primate production colonies which are designed to meet the majority of $\mathrm{NIH}^{\prime}$ s intramural program needs.

* Several of the NIH institutes have contracts for breeding primates for certain specific needs related to their programs. For example, the National Institute of Child Health and Human Development supports a timed-pregnant rhesus monkey colony as a resource for intramural and extramural reproductive studies. The National Heart, Lung, and Blood Institute funds special primate breeding programs for the development of models of atherosclerosis and the production of chimpanzees for the study of serum hepatitis.

* The Food and Drug Administration, Bureau of Biologics, since 1973, has funded contracts with several institutions for primate production programs to eventually meet 100 percent of its needs.

* The Center for Disease Control, since 1976, has internally operated a production colony of rhesus monkeys to eventually meet at least 25 percent of its needs.

Other Federal agencies, sponsors, and performers are also involved in domestic primate production in limited degrees largely to fulfill their own special needs. Appendix D summarizes federally supported domestic breeding programs. 
The diversity of primate species needed, the uncertainties related to foreign supplies, the competition among sponsors for these supplies, the high costs and long time required to establish primate production programs, coupled with the many performers and sponsors involved, all make a coordinated national approach essential. It is imperative that every breeding activity be justified and carefully planned to avoid unnecessary duplication of effort, unnecessary costs, or failure to provide for certain projected needs.

\section{It is recommended that a balanced, nationally coordinated} program of domestic primate production be established.

A program of domestic primate production must consider:

* the species and number of primates required,

* anticipated supply of primates from foreign sources,

* the probability that these foreign sources may be curtailed,

* the status of wild populations of each species,

* the cost of domestic production,

* the breadth of use of each species, and

* our ability to efficiently breed each species in captivity

when determining the species and number of primates that should be bred domestically.

Unfortunately, many of these factors cannot be determined precisely. 1 However, several general conclusions can be drawn from the available data:

1. An adequate domestic production level is required to ensure a continuous supply of primates for critical health activities. This level must be sufficient to provide breeding nuclei to permit expansion as required.

2. It is not practical to expect to meet all of our requirements from domestic breeding at this time. Domestically bred animals are more expensive, and we cannot efficiently breed some species in captivity at the present. Moreover, there may be a need to return to the diversity of natural populations for certain research activities.

${ }_{\text {Chapter IV, Information Requirements and National Primate Program }}$ Monitoring, addresses this issue. 
3. General-purpose breeding colonies ${ }^{1}$ having the potential of being a domestic resource for a wide variety of performers are not likely to be established without the coordination and stimulation that can be afforded through planning on a national scale.

4. Breeding colonies designed to fulfill a unique requirement of a particular performer will be developed by sponsors as the specific need arises.

Presented below is a summary of recommendations developed in light of these conclusions. A detailed discussion of these recommendations, as they relate to individual primate species, can be found in appendix $B$.

It is recommended that, in addition to existing colonies, a series of general-purpose domestic primate production colonies be designed and established according to the following criteria:

1. These activities should be designed to supplement and develop, rather than compete with, the commercial sector.

2. An attempt should be made to enlarge the number of non-Federal organizations operating these colonies.

3. Federally developed programs funded by contract should be so planned and structured as to permit the eventual withdrawal of Federal support.

4. Geographically separated multiple colonies for a species should be encouraged to provide protection against loss from a natural disaster of epidemic disease.

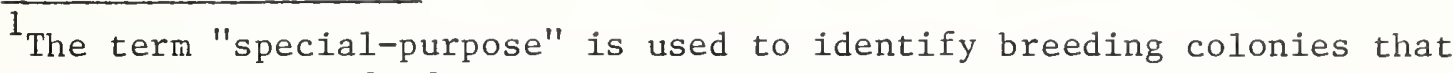
are designed to fulfill the special needs of a single performer or small group of performers. The term "general-purpose" is used to define breeding colonies designed to produce animals for a variety of purposes and performers. 
5. Full advantage should be taken of these domestic primate resources to develop the facilities, technology, and trained personnel that will be required for future primate breeding activities.

6. These production colonies should be available for special research purposes, such as behavioral observations, as long as such research will not interfere with the primary function of production.

It is recommended that production from general-purpose colonies of rhesus monkeys (Macaca mulatta) be expanded to a level which will eventually permit the harvest of 9,000 animals per year, i.e., an increase of 3,500 over the present level. (See appendix B, pp. 53-54)

It is recommenced that at least four general-purpose production colonies of cynomolgus macaques (Macaca fascicularis) be established to yield a net annual total of 3,000 animals by 1982 , and with a potential for expansion to 6,000 per year. (See appendix B, p. 55)

It is recommended that at least two general-purpose production colonies of each of the following species, each capable of producing at least 100 animals annually, be established:

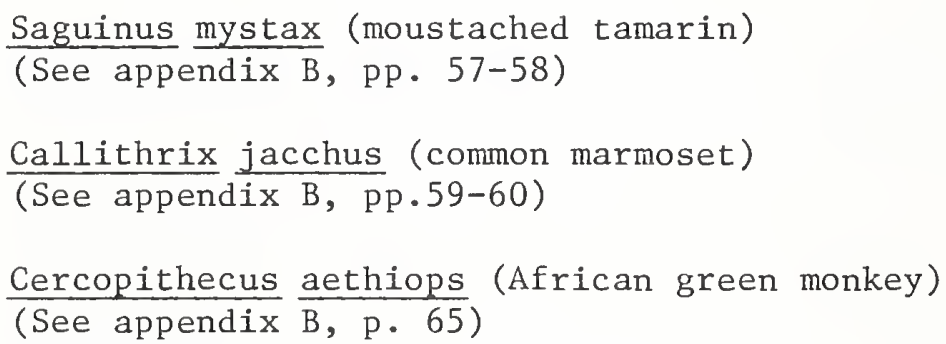

It is recommended that existing colonies be continued and at least one additional general-purpose production colony of each of the following species, each capable of producing at least 150 animals annually, be established:

Aotus trivirgatus (ow1 or night monkey)

(See appendix B, p. 61)

Saguinus oedipus (cottontop tamarin)

(See appendix B, pp. 57-58) 
Current levels of domestic primate production appear to be adequate for several general-purpose species. Colonies of these animals should be maintained at their current levels. However, the design criteria presented above should be incorporated into the operation of these colonies.

It is recommended that general-purpose production colonies already established for Saimiri sciureus (squirrel monkey), be continued at their present level. (See appendix B, p.

Recommendations relating to other species not specifically mentioned above can be found in appendix $B$.

There have been numerous small breeding colonies of primates in the United States for many years. They were maintained by research institutions to help provide for their own needs, and most of them were devoted to rhesus monkeys. Zoos in the United States have also produced primates. Until recently, however, whether in the case of the research laboratory or the zoological garden, primates were bred as something of a sideline and breeding them was not essential. The increasing difficulties in obtaining wild-caught primates have caused many of those institutions to assign a high priority to captive breeding. As a result, a number of zoos and research laboratories possess selected breeding stock of a variety of species, good physical facilities, and professional expertise. They have excellent potential for increased primate production.

It is recommended that zoological gardens and research laboratories be encouraged to make optimum use of their primate colonies for breeding purposes, and that sponsors consider support for such breeding programs.

Some primate species, which are used in very limited numbers or not at al1, may have undiscovered characteristics potentially important for future research. It is possible that, given time, these species may become as important to an overall domestic production program as the more widely used species.

It is recommended that the need for each species of primate in biomedical programs be continually reevaluated to determine annual requirements and that future availability be continually reassessed with the domestic production programs adjusted accordingly. 
Domestic production capability may already exist in many of these less widely known species. These colonies are, therefore, valuable resources in that they may serve as a source of foundation stock for additional breeding should this become necessary. These colonies should be established in the context of acceptable (i.e., supportable) research programs, usually on some aspect of reproductive biology (including behavior). Thus, populations established as semifree ranging colonies in natural or contrived enclosures should provide basic information on social structure, communication, and reproductive behavior which could have, in addition to its basic scientific value, practical significance for the conservation and management of those populations remaining in the native habitat. In addition, the captive populations, if successfully maintained, should be able to provide materials (culls and progeny) for laboratory research. Other arrangements, such as the maintenance of family groups in small enclosures, should also be considered, depending upon the species used and the particular research needs. Although the production of offspring would undoubtedly be less (and more expensive), information gained for laboratory management and utilization would be greater and more rapidly forthcoming.

It is recommended that existing special breeding programs be identified and recognized as important resources and that additional special breeding colonies be encouraged, consistent with particular research programs and the general requirements for more information on a wider variety of species and ecological situations.

In order to ensure the development of a balanced, nationally coordinated program of domestic primate production, sponsors must coordinate their activities and exchange information. The IPSC was established to be such a coordinating body. It has already assisted several Federal sponsors by reviewing their proposals to establish domestic primate production colonies. Joint ventures in this end have been facilitated by the IPSC.

It is recommended that the IPSC continue to review breeding proposals and facilitate the exchange of information between and among sponsors of such programs. Moreover, this service should be available to all sponsors, including those in the private sector. 


\section{Ensuring a Stable Supply of Primates From Foreign Sources}

Nonhuman primates are not indigenous to the continental United States. Therefore, the United States is largely dependent on foreign sources for its primate supplies. These sources are unpredictable and fluctuate according to many factors. A stable, constant supply of these animals is demanded by the nature of the many essential biomedical activities in which primates are used.

It is recommended that appropriate international arrangements be established to lend stability and constancy to foreign sources of primates.

The United States depends, at least in part, upon foreign sources for all species of primates, in varying proportions according to the species. In no case is the United States self-sufficient and in most cases is almost entirely dependent upon imported animals. This should gradually change over the next few years as domestic breeding colonies are established and begin to produce. In the meantime, however, it is necessary to depend on importations not only to meet the demands of research and testing but also to provide the animals required as foundation stock for our breeding projects.

The availability of primates for export from their native countries is fundamentally dependent upon the official policies and practices of the governments of those countries. In most of them, the export of primates is handled by private concerns operating under government control. The United States private firms, which deal direclty with these foreign suppliers, have served the biomedical community in overseas procurement, transporting, conditioning, and delivering the animals to the United States institutions requiring them. Only in situations where this system cannot operate will it be necessary to enter into government-to-government arrangements.

It is recommended that government-to-government arrangements be established only when commercial supply channels are unable to supply our needs.

In some countries, there is hesitancy to authorize export of primates because reliable information on the wild populations is not available. Those countries sometimes require outside assistance in conducting surveys to measure and assess the population dynamics of their feral primates and in providing monitoring/management services so as to maintain and use this valuable resource. As a major primate importer, 
the United States has a special concern about this international problem and should provide financial and technical assistance in its solution. Whenever pussible, such international cooperation should be developed with participation of such organizations as the Pan American Health Organization (PAHO), the World Health Organization (WHO), or the International Union for Conservation of Nature (IUCN); however, this does not rule out direct bilateral cooperation if such arrangements are more appropriate for the situation.

It is recommended that appropriate international assistance be offered to interested source countries in performing surveys of primate populations and in the development of monitoring/ management/conservation services for such populations.

Native primate populations are valuable natural resources that must be conserved. Only through good conservation in source countries will the diversity, availability, and uniqueness of many primate species be preserved. The continuation of these populations is in the interest of the United States in that:

* domestic breeding programs will need to return periodically to these feral populations to maintain necessary genetic diversity;

* certain research activities require primates that have been exposed to their natural environment;

* some species not now used in biomedical programs may have undiscovered characteristics potentially important for future research and can be maintained only through good conservation in source countries;

* the cost of a feral animal, harvested from a managed population, should be less than the cost of an animal domestically raised in the United States;

* if properly managed, primates are a renewable resource valuable to both source countries and the primate user.

It is recommended that programs of international cooperation be established to support primate conservation and production in source countries. 
Primate production can be achieved through the creation of captive production colonies, or through the establishment of isolated reserves in which free-ranging animals are protected and managed for production. In either case, indigenous primate populations are the initial source of these animals; unfortunately, they have not been effectively protected or managed. The technology and procedures for wildlife management, especially for certain game species, have been developed to a high level of efficacy; but very little has been done in this regard for wild primates. Basic information on biologic characteristics, research potentials, and management technology are available for very few primate species. The most widely used species are those for which much of this basic information exists. Consistent with previous experiences, however, it is likely that increased demands will be made for other species as new technologies show them to be particularly useful. Moreover, on few (if any) of the primate species is there the specific information necessary to sustain them as national resources with cultural and economic advantage to the countries in which they are indigenous. In order to encourage the conservation and ecological management of primates, specialized courses of study must be developed.

It is recommended that a course of study and research in wildlife management of primates be developed within a United States university, working in cooperation with foreign counterpart universities, for the preparation of personnel to work in this field.

A major factor in primate loss has been the death of animals during capture, holding, and shipping. Far too many animals are killed during capture or die soon afterwards from inadequate attention to their needs during transport and adaption to captivity. There have been notable improvements in recent years, but mortality from unregulated trapping and holding may sometimes still be as high as 50 percent of the numbers captured. Experience in some special situations and with certain species (e.g., rhesus in India) has demonstrated that these losses can be greatly reduced. Further study and implementation of control procedures are necessary to improve trapping methods, holding, and shipping procedures for all primates.

It is recommended that sponsors supporting activities using wildcaught primates provide support to develop methods that will reduce losses incident to trapping, holding, and shipping. 
The health of peoples of all countries is benefited by research with nonhuman primates. Research with primates for development of new and improved vaccines, new treatments, and new knowledge about diseases and health hazards, are of universal importance. The increasing shortage of primates is, therefore, not only a matter of concern to the United States but extends to all countries and requires full international cooperation.

Long-range programs developed to alleviate the problem should be jointly financed by all consumer countries. Programs such as that of PAHO provide an excellent vehicle for this type of participation. Other international bodies such as WHO and IUCN should be utilized by these consumer countries to develop similar programs. The alternative is for each country to attempt to work out its own arrangements -- with consequent wasteful competition, duplication, and disjointed results.

It is recommended that, to the extent feasible, the United States involve multilateral organizations when developing international programs. It is also recommended that the United States encourage the participation of other consumer countries in such programs.

In order to develop programs of international cooperation, a single organization must be designated to coordinate international aspects of United States interest in the supply of nonhuman primates. Without this reference point, United States sponsors may unknowingly compete for limited foreign supplies and generally create confusion within foreign source countries. The IPSC has the necessary expertise in international affairs and the required stature to create a coordinated and effective program in these matters.

It is recommended that all negotiations and conduct of international cooperative programs to assure adequate primate supplies be coordinated through the IPSC.

International programs designed to provide assistance to source countries in the management of feral primate populations, conservation, animal husbandry, and breeding can be enhanced and strengthened by combining this assistance with joint projects involving primate research and testing. The development of such programs offers an excellent vehicle to expand science and technology cooperation between countries.

It is recommended that international programs in primatology be designed to include, when appropriate, joint primate research activities in countries of origin. 
General objectives, guidance, and policy have been recommended in the above discussion. Specific recommendations for the development of new programs cannot be offered because of the uncertainties and complications which surround foreign affairs. Rather, new specific initiatives consistent with these general criteria must be developed, negotiated, and implemented when the international atmosphere is right -- an operation not conducive to detailed planning. In general, stable foreign supply sources must either be developed or strengthened for all primate species. Particular circumstances that surround individual species will determine the priority with which efforts should be initiated. 
In view of the uncertainties of future primate supplies, it is possible that situations will arise wherein the numbers of animals available of one or more species will be insufficient to meet the minimum overall health needs of this country. This could result in competitive claims for the available animals from performers and sponsors, and it would be necessary to make allocations to satisy the highest priority health programs of this nation. It is, therefore, in the best interest of all concerned in such circumstances that there be a contingency plan for the allocation of available primates.

It is taken as a basic premise that a sponsor or performer providing funds to produce primates has the right and the responsibility for assignment of the primates to their eventual user. In fact, certain programs have already established procedures for allocating primates. The National Heart, Lung, and Blood Institute has developed a procedure for assigning chimpanzees produced in its hepatitis research program, and the National Institute of Child Health and Human Development has a system for apportionment of special-purpose rhesus monkeys derived from its breeding contract. Allocation procedures have also been developed by the Division of Research Resources in order to distribute primates produced as a result of its contracts in support of several breeding colonies.

The Division of Research Services is responsible for allocation of South American primates received via the PAHO primate program and has done so in consultation with the IPSC.

As a general policy, performers and sponsors providing funds that result in primate production will continue to be responsible for allocation of those animals that become available. This applies whether the primates are derived from domestic production colonies, from foreign importation, or from research and testing activities that no longer require them. Performers and sponsors may obtain assistance, if desired, from the IPSC to facilitate the process of allocation.

In the event supplies of one or more species of primates are insufficient to meet critical health needs, it is likely that interagency consultations will be necessary to reach agreement on the distribution in order to meet the most urgent, scientifically worthy, and high-priority health 
demands. The basic order or priority for allocation and use of primates to meet health needs of the nation are: ${ }^{1}$ (1) to fulfill requirements of Federal laws and regulations, e.g., testing of vaccines, and maintaining production of essential biological products; (2) for breeding colonies; and (3) for other biomedical research and development purposes.

The consultative process between sponsors regarding allocation should be facilitated by the IPSC, and an opportunity should be provided for participation of nongovernmental institutions requiring primates. In emergency situations or in the event the consultations do not produce agreement, the IPSC will present the matter to the Assistant Secretary for Health, DHEW.

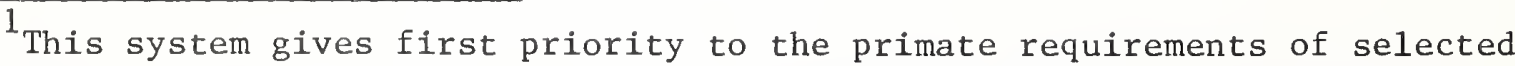
Federal laws and regulations. The IPSC will determine which Federal legal requirements will be given priority over primate needs for other uses. In doing so, the IPSC will attempt to identify those Federal regulations for which primate testing is critical to the fulfillment of regulatory requirements which have the most immediate impact on human health.
} 
CHAPTER IV

INFORMATION REQUIRENIENTS

AND NATIONAL PRIMATE PROGRAM MONITORING

An essential component of a National Primate Program is the development of means to assess current and future requirements for primates and the availability of sources of supplies to meet these requirements. This capability does not currently exist.

\section{It is recommended that each sponsor undertake this assessment process and establish appropriate information systems which allow for this to be a continuous activity.}

Since the concern of each sponsor is, of necessity, parochial, assessment on a national scale must be performed as an additional step.

It is further recommended that the IPSC undertake the responsibility for national assessment by analyzing the aggregate of all sponsors ${ }^{\prime}$ analyses.

In the past, primates have been secured directly by performers through the services of a commercial importer or animal broker. Sponsors of these projects would supply funds enabling these performers to independently secure primates through available channels. Money was the only resource of importance to be managed. The situation has changed. Money alone is insufficient since not all primate species are available from these sources, and those that are available now may not be in the future. Sponsors, in order to carry out their missions, must now manage primate resources much as they do money. Primates are limited, and the demand outstrips supplies. A sponsor must establish priorities among competing interests, making a commitment for support only when sufficient additional resources are available.

Accurate information is essential to this decision process. Information must be collected which identifies a sponsor's total primate requirements (distinguishing those ongoing requirements of funded projects from new 
requirements of proposed projects), the number of primates currently on hand which are available for reassignment, and the availability of primates from sources outside of the sponsor's control.

It is recommended that all sponsors develop a capability, as an integral part of their management information, to define primate requirements for all projects under their sponsorship, identifying:

* species of primate,

* projected annual requirement by year through the life of all projects,

* source of primate supplies or proposed sources (i.e., imported, domestically raised, recycled from other projects or shared use),

* anticipated progeny from the activity which are not needed within the project, and

* the planned disposition of the primates when they are no longer required.

The numbers of primates available to sponsors from sources outside of their direct control cannot be calculated precisely. Rather, these numbers must be determined through an assessment process which would, indirectly, provide such information. Both domestic and foreign sources of primate supplies must be examined.

Assessment of the availability of wild-caught primate supplies is a process surrounded by uncertainty. The status of wild primate populations is only one index that can be used in determination of their availability. Although this index can be determined, access to these supplies cannot since it is controlled by each source country. Foreign supply assessment must, therefore, be based on a combination of many factors such as the historical patterns of primates exported from source countries, expert analysis of wild population levels, accessibility of these supplies, and possibly other factors yet to be identified. Assessment of this nature must be performed from a very wide perspective.

It is recommended that the IPSC undertake responsibility for foreign supply assessment by utilizing the expertise of its staff supplemented with other experts in the field, possibly through a contractual arrangement, as appropriate. This process is intended to be periodically performed as the changing environment may dictate. 
Domestic sources of primate supplies are not subject to the same degree of uncertainty as are foreign sources. Although disease or other disasters may affect them, fairly precise predictions can still be made. Since domestic production at the current stage of development is almost totally under the direct control of sponsors, information concerning these activities must be centrally accumulated so that assessment on a national level can be performed.

It is recommended that each sponsor periodically inform the IPSC
of the status of its production activities, identifying any
primates that may be excess to its immediate need, and its
intentions of future involvement in production activities.

The above information will be most useful in evaluating immediate and short-range situations. In addition, general and long-range information, which provides an overall perspective of the supply/demand picture, must be developed in a manner which is not solely dependent upon the direct participation of sponsors or performers. Specifically, this information should address: (1) the relationship between changes in research emphasis and the impact on primate requirements; (2) the effects of new legislation or regulations that may influence the use or nonuse of primates; (3) the impact of any actions that have been taken as a result of the National Primate Plan; (4) the changing state of knowledge concerning the usefulness of the various species of primates to the biomedical community; (5) the effect of the private sector's involvement in this field from both the demand and supply orientations; and (6) other indices that may paint a clearer picture.

Many avenues must be pursued in the development of this type of information. The organization undertaking this task requires an extensive network of contacts and must be knowledgeable in many areas of expertise.

It is recommended that the IPSC assume the responsibility of developing this overall perspective in an efficient and effective manner and provide for its periodic updating.

It is not intended that the IPSC develop an extensive information system to specifically address these questions but rather utilize the many already existing systems, especially those within the public sector, such as the United States Department of Agriculture reports on the use of animals in research and import records from the Center for Disease Control and the Departments of Interior and Commerce, supplementing 
them where necessary. The services of an organization nationally known and respected by the biomedical community may be sought to provide additional staff support in the analysis and synthesis of this information.

The responsibility of collecting and analyzing this information is that of the biomedical community. Sponsors have an important role in establishing trends in this community and must take an active and aggressive role in the development of this understanding. The IPSC, being the central focal point for sponsors, should be used in the development of a national perspective sensitive to national health needs and provide for a forum where plans can be developed effecting positive change within the primate usage system. 
CHAPTER V

ACTION IMPLEMENTATION

The success of this plan rests, largely, on the adherence to its recommendations by individual performers, most of whom are affiliated with academic institutions and/or professional societies or trade associations. The acceptance of these recommendations by these institutions and societies will increase the liklihood of their recognition by the individual performers; it will also simplify the interactions that these performers will have with their institutional administrations as they attempt to implement these recommendations at the local level.

It is recommended that, through the IPSC, academic institutions, consortia of such institutions, professional societies and trade associations, and other user groups be fully informed of this plan, be specifically invited to comment on its goals and content, and be strongly encouraged to participate with the Federal and other sponsoring agencies in implementing its recommendations.

\section{A. Current Status}

A number of actions have already been taken towards the implementation of this plan. They are summarized below.

Ensuring the Most Effective Use of Primates

* Criteria for preparing and reviewing research proposals using nonhuman primates have been formulated by the IPSC and accepted by Federal sponsors.

* A recycling program has been developed for NIH intramural performers and is in the final stages of implementation.

* Recycling of primates between sponsors has been facilitated through the efforts of the IPSC.

* A contract has been awarded by NIH for the development and operation of a Primate Supply Information Clearinghouse, as the principal component of a national primate users' service. 
* The NIH has established a number of general-purpose production colonies by means of contracts with non-Federal organizations.

* Since 1973, FDA's Bureau of Biologics has moved to establish four specifically committed breeding colonies to meet regulatory needs. The FDA plans to be self-sufficient for specifically needed primates in programs under their sponsorship.

* The Center for Disease Control and the Navy have each established their own general-purpose production colony.

* The seven Regional Primate Research Centers, through specialpurpose breeding colonies, are producing about 50 percent of their own primate needs, and have the goal of becoming as self-sufficient as possible.

* Several of the NIH institutes have established special-purpose breeding colonies.

* A rehabilitation, reuse, and breeding center for chimpanzees is being developed by a non-Federal organization with funding from the NIH.

\section{Ensuring a Stable Supply of Primates From Foreign Sources}

* Some New World species of primates have been made available for research purposes as a result of the PAHO primate production and conservation program.

* Consultations and negotiations have been conducted with foreign governments and international organizations.

* Several surveys of primate populations have been conducted with funding from the NIH, and additional surveys are now in preparation.

* The Institutes of Laboratory Animal Resources, National Academy of Sciences, has begun to develop a guide for conducting field studies. 


\section{B. Future Requirements}

Presented below are preliminary estimates of additional resources required to implement this plan. These estimates include only those resources which are necessary to begin new initiatives or expand current programs to recommended levels. (Administrative support of the IPSC, while not a new initiative, is also included.)

While this plan calls for the continuation of many previously initiated programs, resources required to carry these programs forward are not presented. It is assumed that these costs will be addressed by the sponsor operating the program when additional funding becomes necessary.

Ensuring the Most Effective Use of Primates

* Recommendations presented within this section of the plan address procedural and managerial aspects of sponsor's activities. Any additional expense incurred as a result of these recommendations is expected to be offset by a reduction in the need for additional primates.

* Funding of a contract for the operation of a primate users' service has been provided by the NIH through 1979. Additional support will be required to expand the service after this date.

* Staff support for the IPSC must be increased in order for it to effectively provide the necessary assistance to sponsors in this area and to coordinate the entire National Primate Program.

\section{Production of Primates in the United States}

* This plan calls for the expansion of the current domestic primates breeding program by increasing the number of general-purpose colonies. The enlargement of some of the existing colonies and the establishment of a number of additional colonies are recommended. It is anticipated that $\$ 4.12$ million will be required over 2 years to establish these colonies. Approximately $\$ 4.86$ million will be required to maintain these colonies each year thereafter.

\footnotetext{
${ }^{1}$ Appendix E contains a comprehensive list of responsibilities assigned to the IPSC as recommended within this plan.
} 
* Existing general-purpose primate production colonies are to be maintained at their currently designed full-production level or expanded until they reach this level. Since these colonies have been previously funded and established as ongoing operations, any additional funds required by them will be covered by the operating sponsors, independent of this plan.

* This plan further recommends the eventual withdrawal of direct Federal funding of all commercial general-purpose production colonies. In order to achieve this end, these colonies are to be funded at a decreasing level until they become self-supported through the sale of progeny.

\section{Ensuring a Stable Supply of Primates From Foreign Sources}

Since international programs will be developed at varying times depending upon many unpredictable circumstances, an itemized statement of resource requirements cannot be offered. However, in order to facilitate the definition and initiation of these programs, funds, restricted to this overall effort, must be made available for program planning and development. These funds will be administered by the IPSC to support activities such as primate population surveys, field studies, and the initial development of programs for primate production. Approximately $\$ 150,000$ a year will be required for such activities. Once operational, international programs will be administered and operated by those sponsors who benefit from such programs. It is intended that, where appropriate, these programs will become self-supporting through the sale of primates to performers. Programs structured in this way will transfer the financial burden of their operation to the health activities requiring primates. Since funding is initially allocated to these health activities, no additional funding will be required to maintain international programs once they are established. 
Other more specific recommendations presented within this plan require the following resources:
* Over a 3-year period, $\$ 50,000$ is required to develop improved methods of capturing and handling wild primates.
* Over a 3-year period, $\$ 100,000$ is required to establish
a manpower development program for wild primate management.

\title{
Information Requirements and Program Monitoring
}

\begin{abstract}
* Additional resources will be required by the IPSC to undertake its responsibilities for data collection and analysis. Outside contractual assistance will be sought to supplement its current capability in this area.
\end{abstract}

1. Consultants will be engaged for foreign supply assessment. Approximately $\$ 30,000$ a year will be required to support this activity .

2. Data from existing information systems and other sources will be compiled and processed through contractual arrangements or interagency agreements at an estimated annual cost of $\$ 15,000$.

3. Long-range analysis of primate requirements, analysis of new developments, and monitoring of the overall National Primate Program will be performed in conjunction with an organization nationally known and respected by the biomedical community. Approximately $\$ 45,000$ will be required annually to support this activity. 
Table 4

Additional Support for the Continuation of the

National Primate Program

\begin{tabular}{llll}
\hline Actions & FY79 & FY 80 & FY 81 \\
\hline & & In Thousands of Dollars
\end{tabular}

Ensuring the most effective use of nonhuman primates

Users' service

25

35

Domestic production of primates*

$\begin{array}{lrrr}\text { Macaca mulatta } & 3,675 & 3,430 & 2,450 \\ \text { Macaca fascicularis } & 2,700 & 2,520 & 1,800 \\ \text { Saguinus mystax } & 140 & 125 & 90 \\ \text { Saguinus oedipus } & 105 & 95 & 70 \\ \text { Callithrix jacchus } & 140 & 125 & 90 \\ \text { Cercopithecus aethiops } & 325 & 295 & 210 \\ \text { Aotus trivirgatus } & 230 & 210 & 150 \\ \quad \text { Subtotal } & 7,315 & 6,800 & 4,860\end{array}$

Ensuring a stable supply of primates from foreign sources

General

$150 \quad 150 \quad 165$

Capturing methods

$11 \quad 23 \quad 25$

Wild primate management

80

84

92

Information requirements and program monitoring

Foreign supply assessment

Domestic breeding status

Overall supply/demand assessment

General data processing

$\begin{array}{rrr}30 & 30 & 35 \\ 5 & 5 & 7 \\ 45 & 45 & 45 \\ 15 & 15 & 15\end{array}$

IPSC Administrative Support

Positions

(3) (4)

Salaries and other

187

212

235

\begin{tabular}{llll}
\hline Total & 7,838 & 7,389 & 5,514 \\
\hline
\end{tabular}

*Figures are calculated with the assumption that initial breeding stock will be acquired during FY 79 and FY 80. 
APPENDIX A

PRESENTATIONS OF PRIMATE REQUIREMENTS 

Nonhuman primates have become essential in a number of health-related activities, including basic biological and behavioral research as well as for biological production and for testing products. In this document, the aggregate of these uses has been referred to as health needs. Fourt general groups of activities are identified in the biomedical use of primates.

* Legal and Regulatory. Procedures prescribed by law or regulation, e.g., those pertaining to production, potency testing, and safety testing of viral vaccine seed suspensions and vaccine lots of licensed products. 1

* Biological Production. Preparation of biological material such as experimental vaccines, tissue cultures, serum products, and biological diagnostic reagents. This includes activities using primates for production phases of thse materials which are not specifically required by law or regulation.

* Testing. Evaluation of efficacy or safety of products for prophylactic, therapeutic, and nutritional purposes. This includes activities concerned with efficacy and safety testing of vaccines prior to licensure, and of other compounds, materials, apparatuses, or other devices prior to approval for marketing; it also includes activities using primates tissues for reference diagnostic purposes.

* Research. The use of primates as models for the study of various disease processes or the development of information useful in understanding human behavior. Research on the biology of various primate species is also included here since this is fundamental to the better use of these animals in all of the aforementioned activities.

The following tables represent a compilation of data on all nonhuman primates required for each categorical activity. The numbers contained within these tables are based upon analysis of usage trends over the past several years, current researc and development priorities relating to use of primates, and the opinions of experts in this field. They represent the best available data and can be expected to reasonably reflect national requirements for the next few years.

\footnotetext{
I Title 21 CFR 600-680 (Food \& Drugs; Biologics)
} 
Table 5 (page 45) presents, by sponsor and national health need, the annul aggregate number, regardless of species, of all nonhuman primates required during the year 1977 to maintain the current level of activity. Requirements are stated as the number of new animals to be acquired via importation or from domestic breeding programs; they do not include breeding stock for proposed breeding programs. A primate requirement includes timed pregnancies, neonates, or other fetal material. This table is presented for comparative purposes, and it is not to imply that all primate species are of equal importance or necessarily interchangeable.

The estimated numbers required are listed by national health need and species in Table 6 (page 46), and by sponsor and species in Table 7 (page 47). The remaining tables array the requirements for each species by sponsor and national health need.

The National Primate Plan has used this information as a foundation from which to present and justify recommended future action. It is recognized that these numbers represent the status quo and that actual needs will vary. Therefore, as an overall part of the plan, an assessment system has been proposed as a mechanism for the reappraisal of primate requirements over time as new information is generated. Chapter IV, Information Requirements and National Primate Program Monitoring, further discusses this mechanism. 
Table 5

Estimated Annual Requirements for Nonhuman Primates

by Sponsor and National Health Need*

\begin{tabular}{|c|c|c|c|c|c|}
\hline Sponsor & $\begin{array}{l}\text { Required } \\
\text { by Law or } \\
\text { Regulation }\end{array}$ & $\begin{array}{l}\text { Production } \\
\text { of } \\
\text { Biologics }\end{array}$ & Testing & Research & Total \\
\hline $\begin{array}{l}\text { Federal Government } \\
\text { DHEW } \\
\text { ADAMHA } \\
\text { CDC } \\
\text { FDA } \\
\text { NIH } \\
\text { Extramural } \\
\text { Intramural } \\
\text { DoD } \\
\text { Air Force } \\
\text { Army } \\
\text { Navy } \\
\text { Other } \\
\text { EPA } \\
\text { ERDA } \\
\text { NASA } \\
\text { NSF } \\
\text { VA } \\
\text { Other Agencies } \\
\text { Industry } \\
\text { Pharmaceutical/Biological } \\
\text { Other } \\
\text { Other** }\end{array}$ & 2,450 & 200 & $\begin{array}{r}75 \\
220 \\
250\end{array}$ & $\begin{array}{r}600 \\
270 \\
410 \\
11,430 \\
1,355 \\
\\
781 \\
1,930 \\
675 \\
560 \\
770 \\
110 \\
275 \\
254 \\
862 \\
\\
1,200 \\
\\
1,015\end{array}$ & $\begin{array}{r}600 \\
545 \\
3,080 \\
11,430 \\
1,355 \\
\\
781 \\
2,180 \\
675 \\
560 \\
770 \\
110 \\
275 \\
254 \\
862 \\
\\
9,420 \\
1,015\end{array}$ \\
\hline Total & 6,950 & 1,000 & 3,465 & 22,497 & 33,912 \\
\hline
\end{tabular}

"Based on 1977 data

* Other includes requirements of activities funded by state and local governments, foundations and academic institutions. 
Table 6

United States Estimated Annual Requirements for Nonhuman Primates by National Health Need and Species*

\begin{tabular}{|c|c|c|c|c|c|}
\hline National Health Need & $\begin{array}{l}\text { Required by } \\
\text { Law or } \\
\text { Regulation }\end{array}$ & $\begin{array}{l}\text { Production } \\
\text { of } \\
\text { Biologics }\end{array}$ & Testing & Research & Total \\
\hline Rhesus & 5300 & 200 & 1160 & 7355 & 14015 \\
\hline Cynomologus & 900 & & 100 & 5005 & 6005 \\
\hline Other Macaque & & & & 995 & 995 \\
\hline Saquinus species & & & 800 & 1390 & 2190 \\
\hline Common Marmoset & & & & 170 & 170 \\
\hline Owl Monkey & & & 250 & 1215 & 1465 \\
\hline Chimpanzee & & & 40 & 140 & 180 \\
\hline Gibbon & & & & 100 & 100 \\
\hline Baboon & & & & 1282 & 1282 \\
\hline African Green Monkey & 750 & 500 & 15 & 810 & 2075 \\
\hline Squirrel Monkey & & 300 & 1100 & 3045 & 4445 \\
\hline Other & & & & 990 & 990 \\
\hline Total & 6950 & 1000 & 3465 & 22497 & 33912 \\
\hline
\end{tabular}

*Based on 1977 data 
Table 7

Estimated Annual Requirements for Nonhuman Primates

by Sponsor and Species*

\begin{tabular}{|c|c|c|c|c|c|c|c|c|c|c|c|c|c|}
\hline Sponsor & 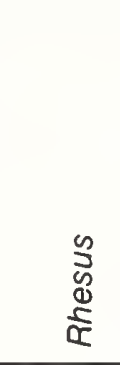 & $\begin{array}{l}0 \\
\text { o } \\
0 \\
\text { ह } \\
\vdots \\
\vdots \\
0\end{array}$ & 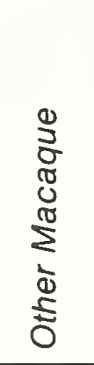 & 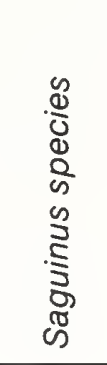 & 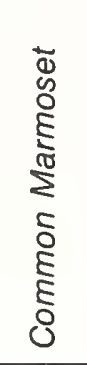 & $\begin{array}{l}\overrightarrow{0} \\
\frac{1}{5} \\
\frac{0}{2} \\
\frac{1}{3} \\
0\end{array}$ & 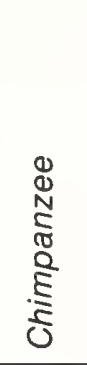 & $\begin{array}{l}\delta \\
0 \\
0 \\
0\end{array}$ & $\begin{array}{l}5 \\
8 \\
8 \\
\mathbb{0} \\
\infty\end{array}$ & 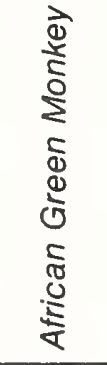 & 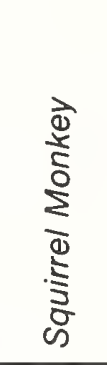 & $\begin{array}{l}\text { ఏ } \\
\text { ఏ }\end{array}$ & $\begin{array}{l}\bar{\varpi} \\
\text { 음 }\end{array}$ \\
\hline \multicolumn{14}{|l|}{$\begin{array}{l}\text { Federal Government } \\
\text { DHEW }\end{array}$} \\
\hline ADAMHA & 150 & 80 & 110 & & & & 5 & & 20 & 5 & 150 & 80 & 600 \\
\hline CDC & 360 & & & 60 & & 90 & 10 & & & 15 & 10 & & 545 \\
\hline FDA & 2280 & 305 & & 300 & & 50 & 25 & & 10 & 50 & 60 & & 3080 \\
\hline \multicolumn{14}{|l|}{$\mathrm{NIH}$} \\
\hline Extramural & 3500 & 2400 & 600 & 700 & 150 & 660 & 100 & 100 & 500 & 600 & 1420 & 700 & 11430 \\
\hline Intramural & 700 & 70 & 15 & 400 & & 35 & & & 20 & 50 & 20 & 45 & 1355 \\
\hline \multicolumn{14}{|l|}{ DoD } \\
\hline Air Force & 550 & 50 & 25 & & & & 6 & & 95 & 25 & 30 & & 781 \\
\hline Army & 800 & 1050 & & & & 100 & & & 80 & & 150 & & 2180 \\
\hline Navy & 150 & 100 & 25 & & & & & & 150 & 50 & 200 & & 675 \\
\hline Other & 180 & 380 & & & & & & & & & & & 560 \\
\hline EPA & 165 & 50 & 25 & & & & & & 60 & 15 & 450 & 5 & 770 \\
\hline ERDA & 20 & 40 & & & & & & & & & 50 & & 110 \\
\hline NASA & 40 & 60 & 50 & & & & & & 25 & & 100 & & 275 \\
\hline NSF & 125 & 20 & 35 & & & & 2 & & 2 & & 10 & 60 & 254 \\
\hline $\begin{array}{l}\text { VA } \\
\text { Other Agencies }\end{array}$ & 505 & 30 & 85 & & 20 & 30 & 2 & & 90 & 45 & 55 & & 862 \\
\hline \multicolumn{14}{|l|}{ Industry } \\
\hline $\begin{array}{l}\text { Pharmaceutical/ } \\
\text { Biological }\end{array}$ & 4300 & 1000 & & 700 & & 500 & 20 & & 100 & 1200 & 1500 & 100 & 9420 \\
\hline Other ${ }^{* *}$ & 190 & 370 & 25 & 30 & & & 10 & & 130 & 20 & 240 & & 1015 \\
\hline Total & 14015 & 6005 & 995 & 2190 & 170 & 1465 & 180 & 100 & 1282 & 2075 & 4445 & 990 & 33912 \\
\hline
\end{tabular}

"Based on 1977 data

*"Other includes requirements of activities funded by state and local governments, foundations and academic institutions. 


\section{Table 8}

\section{Estimated Annual Requirements for Nonhuman Primates by Species, Sponsor and National Health Need*}

\section{Part 1 of 3}

\begin{tabular}{|c|c|c|c|c|c|c|c|c|c|c|c|c|c|c|c|c|}
\hline \multirow[b]{3}{*}{ Sponsor } & \multicolumn{4}{|c|}{ Rhesus } & \multicolumn{4}{|c|}{ Cynomolgus } & \multicolumn{4}{|c|}{ Other Macaque } & \multicolumn{4}{|c|}{ Saguinus species } \\
\hline & \multicolumn{16}{|c|}{ Health Needs* * } \\
\hline & 1 & ॥ & III & IV & I & II & III & IV & 1 & II & III & IV & 1 & II & IIII & IV \\
\hline \multirow{2}{*}{\multicolumn{17}{|c|}{$\begin{array}{l}\text { Federal Government } \\
\text { DHEW }\end{array}$}} \\
\hline & & & & & & & & & & & & & & & & \\
\hline ADAMHA & & & & 150 & & & & 80 & & & & 110 & & & & \\
\hline CDC & & 200 & 60 & 100 & & & & & & & & & & & & 60 \\
\hline FDA & 2100 & & & 180 & 300 & & & 5 & & & & & & & 200 & 100 \\
\hline \multicolumn{17}{|l|}{ NIH } \\
\hline Extramural & & & & 3500 & & & & 2400 & & & & 600 & & & & 700 \\
\hline Intramural & & & & 700 & & & & 70 & & & & 15 & & & & 400 \\
\hline \multicolumn{17}{|l|}{ DoD } \\
\hline Air Force & & & & 550 & & & & 50 & & & & 25 & & & & \\
\hline Army & & & 100 & 700 & & & 100 & 950 & & & & & & & & \\
\hline Navy & & & & 150 & & & & 100 & & & & 25 & & & & \\
\hline Other & & & & 180 & & & & 380 & & & & & & & & \\
\hline EPA & & & & 165 & & & & 50 & & & & 25 & & & & \\
\hline ERDA & & & & 20 & & & & 40 & & & & & & & & \\
\hline NASA & & & & 40 & & & & 60 & & & & 50 & & & & \\
\hline NSF & & & & 125 & & & & 20 & & & & 35 & & & & \\
\hline VA & & & & 505 & & & & 30 & & & & 85 & & & & \\
\hline \multicolumn{17}{|l|}{ Other Agencies } \\
\hline \multicolumn{17}{|l|}{ Industry } \\
\hline $\begin{array}{l}\text { Pharmaceutical/ } \\
\text { Biological }\end{array}$ & 3200 & & 1000 & 100 & 600 & & & 400 & & & & & & & 600 & 100 \\
\hline Other & & & & & & & & & & & & & 1. & & & \\
\hline Other*** & & & & 190 & & & & 370 & & & & 25 & & & & 30 \\
\hline Total & 5300 & 200 & 1160 & 7355 & 900 & & 100 & 5005 & & & & 995 & & & 800 & 1390 \\
\hline
\end{tabular}

"Based on 1977 data.

${ }^{* *}$ I = Required by Law or Regulation; II = Production of Biologics; III = Testing; IV = Research.

**"Other includes requirements of activities funded by state and local governments, foundations and academic institutions. 
Table 9

Estimated Annual Requirements for Nonhuman Primates

by Species, Sponsor and National Health Need ${ }^{*}$

Part 2 of 3

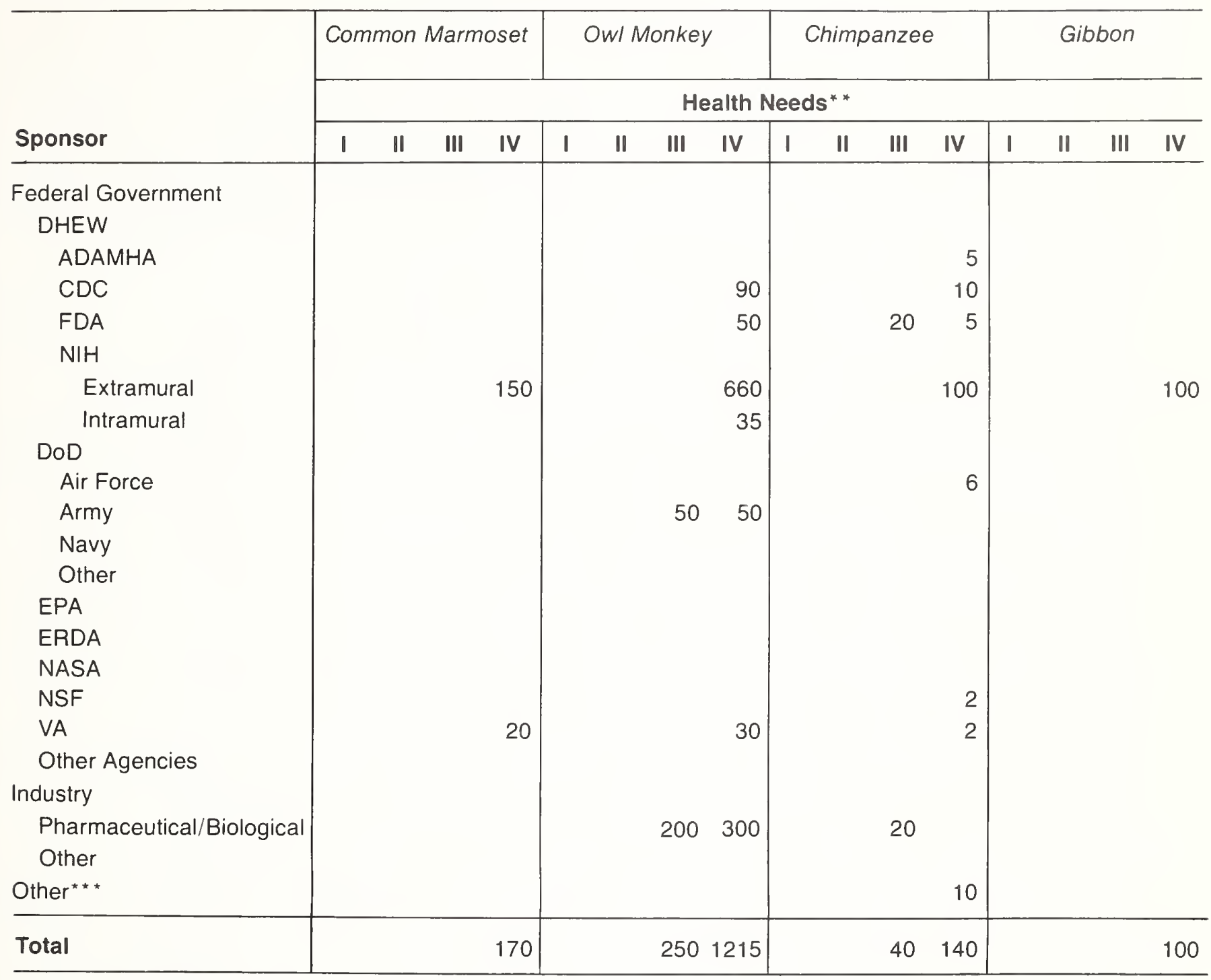

*Based on 1977 data

${ }^{*}$ I = Required by Law or Regulation; $\|$ = Production of Biologics; $I I I=$ Testing; IV = Research

*** Other includes requirements of activities funded by state and local governments, foundations and academic institutions. 
Table 10

Estimated Annual Requirements for Nonhuman Primates by Species, Sponsor and National Health Need* Part 3 of 3

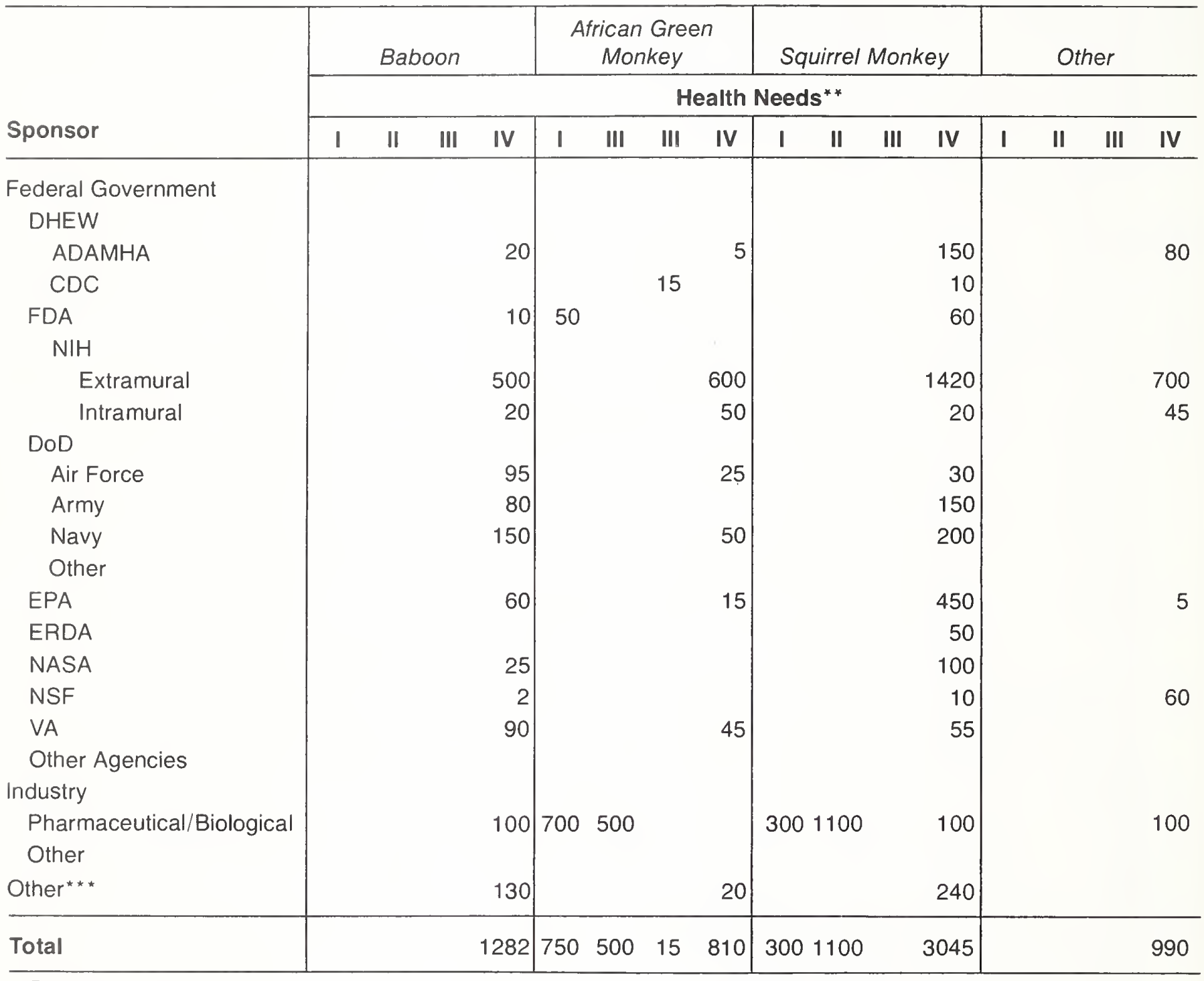

*Based on 1977 data

${ }^{* *} \mid=$ Required by Law or Regulation; II = Production of Biologics; III = Testing; IV = Research.

" * "Other includes requirements of activities funded by state and local governments, foundations and academic institutions. 
APPENDIX B

DISCUSSION OF MAJOR PRIMATE SPECIES 


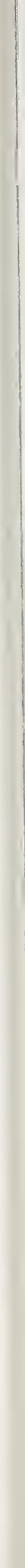


Macaca mulatta (Rhesus Monkey)

\section{$\underline{\text { Utilization }}$}

This macaque has always been considered the general purpose primate for experimental purposes. It is also by far the most widely used primate for the production and testing of biological products. Large numbers are used for safety testing of poliomyelitis and other vaccines. As a result of a long history of its use and the data that has been developed with respect to the anatomy, physiology, and behavior of this animal, it is highly preferred for many experimental purposes. Restrictions of supplies within the past few years have led to substitutions of other primates, especially Macaca fascicularis.

\section{Foreign Sources}

Geographically, the rhesus monkey is found within India and neighboring countries. The number available has dropped considerably in recent years. In 1972, an estimated 50,000 of these animals were exported from India, the primary source country. In 1974, the Government of India authorized a worldwide export of 30,000, approximately 20,000 of which were received in the United States. In 1975, and 1977, the Indian export quota was 20,000 rhesus per year worldwide, of which approximately 12,000 per year came to the United States. Very small numbers of these monkeys were occasionally exported from Bangladesh during that period.

Late in 1977, the Indian government announced a ban on all exports of primates, which became effective April 1, 1978. Although there remains the possibility of obtaining rhesus from other countries of southern Asia, the wild populations are relatively small and, even at best, would allow the withdrawal of limited numbers of animals.

\section{Production in United States}

After making allowance for some animals as replacement breeding stock, the present breeding colonies of rhesus in the United States should yield a net of 5,500 annually by 1980. Nearly all of this production is federally supported. The pharmaceutical industry has recently initiated a rhesus breeding project to meet needs for vaccine testing, but is unable to carry out its plans for lack of breeding stock.

Currently the 5,500 would meet less than 50 percent of our overall needs and, with no imports available, would have to be assigned first to meet 100 percent of the needs requirements for legally required vaccine testing. In this situation, some progeny must be diverted to expand breeding colonies, a process which will take several years. With no new animals coming into the "pool" of the 5,500 produced each year, as many as 2,730 males and 2,570 females could go to vaccine testing. The remaining 180 females and 20 males would be used to expand breeding programs. After reaching 
sexual maturity in the fourth year and assuming an optimistic net harvest rate of 50 percent, the yield would be an additional 90 animals. Thus, the overall output from our domestic breeding operations would be increasing at a rate of 90 per year in the fourth year and incrementally increase as these new animals reach sexual maturity. If 14,000 animals are required per year and the current capacity is 5,500, it would take a total of 16 years before any animals could be made available to activities other than those legally required, and then only about 1,500 animals. A total of 20 years would be required before we could become self-sufficient in meeting our total needs for this species.

Among the breeding programs, there are at least eight general-purpose production colonies distributed over a wide geographic area, assuring adequate protection against colony disaster. In addition to these general-purpose breeding colonies, a number of smaller special-purpose breeding colonies have been established. It is estimated these will produce approximately 2,000 animals per year. In addition, it is expected that recycling will result in a net savings of several thousand per year.

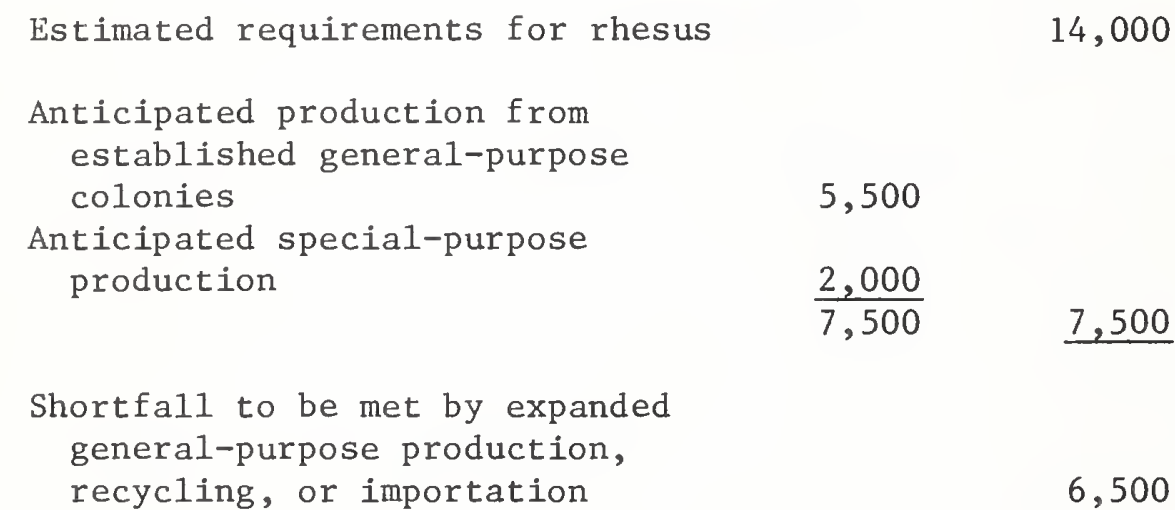

Recommendations

In order to meet the nation's needs, the general-purpose rhesus production program should be expanded to a level allowing an annual harvest of 9,000 animals per year, i.e., an increase of 3,500 over the level of the present program. If recycling and importation do not provide the needed additional animals, domestic breeding may have to be expanded further. 
Macaca fascicularis (Cynomolgus or Long-Tail Macaque)

\section{$\underline{\text { Utilization }}$}

This macaque is second only to the rhesus in the numbers used for medical purposes in the United States. Approximately 6,000 were required in 1977. As is the rhesus, this species is also considered to be a generalpurpose primate, and for many uses, it is substituted for that species. Moreover, for some purposes it is considered preferable, because it is more tractable and is slightly smaller. It is likely that the trend of substituting the cynomolgus for the rhesus has accelerated as the supplies of rhesus have become more and more restricted. However, a major field of use in which the cynomolgus has not yet been accepted as a substitute for the rhesus is in the safety testing of vaccines, especially poliomyelitis vaccine.

\section{Foreign Sources}

This primate is available from Southeast Asian countries where it remains relatively plentiful. However, the destruction of the habitat and other competition from man are causing a continuous reduction in the population of this animal in its native countries, and wild populations will certainly continue to diminish. Thailand has recently prohibited their export; the other source countries for the United States are Indonesia, Malaysia, and the Philippines.

\section{Production in United States}

A few cynomolgus macaques are bred by research institutions for their own use. In 1976, the Division of Research Resources, National Institutes of Health, awarded a contract to produce 150 of these animals per year for the scientific community in general. That goal should be attained by 1980 .

\section{$\underline{\text { Recommendations }}$}

The supply of the wild-caught long-tail macaque will probably remain about the same for the next few years. The relative abundance and the widespread geographic distribution of this species make it less 11kely that foreign supplies will be totally eliminated in the foreseeable future. However, the lack of breeding stock to rapidly expand our rhesus production colonies, and the increasing use of the cynomolgus makes it necessary to place more emphasis on the establishment of large colonies of this macaque. The United States should have sufficient breeding capacity to meet at least half of the nation's needs for M. fascicularis. Based upon the estimated 1977 requirements, an ultimate production goal of 6,000 cynomolgus per year is proposed. It is recommended that at least four colonies be established as soon as possible for an annual production for 1982 of 3,000 and a potential for expansion to 6,000 . 
Other Macaque Species

Utilization

It is estimated that at least 1,000 macaques, other than Macaca mulatta and $\underline{M}$. fascicularis, are needed per year. These macaques are used almost entirely for research purposes, rather than for biological production or testing. The fields of research are numerous and, as a group, the neurosciences, including behavioral studies, seem to have the greatest need for them.

\section{Foreign Sources}

M. nemestrina (pig-tailed macaques) are no longer obtainable from Thailand and are becoming difficult to find in Malaysia. They remain relatively plentiful in parts of Indonesia. M. arctoides (stumptailed macaques), M. cyclopis (Formosan macaques), and M. fuscata (Japanese macaques) are rare and virtually impossible to obtain from the wild. M. radiata

(bonnet macaques) are found in large numbers in India, but this species has not been used to any extent for biomedical purposes, and the demand is smal1.

\section{Production in United States}

Small breeding colonies of these macaques are to be found at the Regional Primate Research Centers and elsewhere in the United States. However, in general, they produce animals only for their own institutional needs. These colonies could conceivably serve as the source of foundation stock for other colonies and are, therefore, valuable resources that should be so recognized and supported. This is justifiable because of the uniqueness of these species for research purposes now known and yet to be discovered.

\section{Recommendations}

Since many species of macaques are used in limited numbers for a wide variety of specific research projects and most of these species will probably continue to be available through importation over the next several years, it is impractical to recommend the development of generalpurpose production colonies on a national level. However, all sponsors are urged to review their specific needs and establish production programs to meet those needs where appropriate. The use of these species should be continually reassessed by the IPSC to determine if breeding colonies should be recommended on a national scale. Additionally, consideration should be given to studying the comparative value of those animals still available in large numbers from the wild as a substitute for other macaques which are not as available. 
Saguinus spp. (Tamarins)

\section{$\underline{\text { Utilization }}$}

Numerous species of Saguinus have special value for biomedical research. S. mystax is especially needed because of its susceptibility to hepatitis A virus; . oedipus is important for work in viral oncology; . fuscicollis, S. nigricollis, S. labiatus, and others are used in virology, immunology, dental studies, reproductive physiology, behavioral studies, and other research. There is evidence that research demands for these species will increase. Their potential use as test animals for hepatitis and for cancer research suggests that large numbers will be needed over a long period of time. In 1977, at least 2,200 animals are required. More could effectively be used for much needed research were they available.

\section{Foreign Sources}

These primates, which are found within the tropical and montane forests of South America, have decreased in number over recent years. One species, $\underline{\text { S }}$ oedipus, has even been listed as endangered. The export of these animals, accordingly, has been prohibited by most South American countries, and supplies are practically unavailable via commercial channels. However, in recognition of their special value and the urgent need for them in health research, small numbers have been made available to the United States both directly and via an international program being initiated by PAHO. This program gives emphasis to the captive breeding of Saguinus species in source countries and should provide for a part of the research needs.

\section{Production in United States}

Domestic production of various Saguinus species within the private sector is limited to a few colonies at several institutions which breed them for their own internal use. Government-supported breeding exists only on a small scale with an annual production level of 460 animals expected in 1980. Of these animals, only 60-100 S. oedipus are made available for general use with the remainder allocated to special programs.

\section{$\underline{\text { Recommendations }}$}

Domestic production of $\underline{S}$. oedipus should be increased with an additional breeding colony capable of producing 150 weanling-age animals per year. The progeny of this colony would be made available for general-purpose use to a wide spectrum of performers.

Since $\underline{S}$. mystax is not available at all to the general research community and the demand is great involving many performers, two colonies, each 
capable of producing at least 100 animals a year, should be established to supply this community.

Production of other Saguinus species on a large scale for general use is not justified at this time because of the limited numbers required, mostly for special use by a small number of performers. The IPSC, however, should keep abreast of their value to the biomedical community, recommending additional breeding if this situation should change.

Continuation of the PAHO program is essential in order to meet a portion of the shortfall between domestic production and research requirements. Continued support of this program is strongly recommended. 
Callithrix jacchus (Common Marmoset)

\section{$\underline{\text { Utilization }}$}

This small Brazilian primate has been used very little in the United States but is becoming valuable in Europe, and especially in Great Britain, for a number of research and testing purposes. Some of the most notable of these are reproductive physiology (including testing of antifertility products), teratology, toxicology, infectious diseases, drug safety, and a variety of behavioral studies.

Since export of this animal from Brazil is currently prohibited, those being used in Europe come from domestic breeding programs which have proved to be practical and cost-effective. Only small numbers have been used in the United States; however, the potential of this species as an important animal model makes it imperative to consider it within the National Primate Plan.

\section{Foreign Sources}

The common marmoset is found in various forest formations in eastern Brazil. This animal is not available through normal trade channels because of export restrictions imposed by the Brazilian government.

\section{$\underline{\text { Production in United States }}$}

Only one small general-purpose production colony of common marmosets is known to exist at this time. This colony, supported by a Public Health Service grant, is expected to produce between 100 to 150 animals per year. Special breeding programs are also limited and may, in fact, not exist. Even within the seven Regional Primate Research Centers, the major scientific resource for the study of primates as they relate to man, no production of this animal occurs, and the same is probably true throughout the United States.

\section{$\underline{\text { Recommendations }}$}

While there has been little breeding and use of this animal in the United States, recent experience in Europe indicates it is a valuable model for research and testing and that it is a highly cost-effective animal to breed in captivity. Its relatively short gestation period and frequency of twinning result in highly productive breeding colonies. This animal has the potential of becoming more generally useful because of its small size and ease of handling in the laboratory. It cannot be obtained through normal channels, and domestic breeding should be initiated to produce a sufficient number to begin using them to meet new requirements for nonhuman primates in the United States. 
Initially, it is recommended that two colonies, each designed to produce at least 100 animals, be established in geographically separated areas. The progeny of these colonies should be made available to a wide spectrum of performers for general use. In addition, in an attempt to reduce the demand for other species that are more difficult to obtain, sponsors involved in categorical research areas should devote some effort to determining the suitability" of this primate for their performers. 
Aotus trivirgatus (Owl Monkey or Night Monkey)

Utilization

The owl monkey, being the only suitable model currently known for human malaria chemotherapy and immunology studies, is considered essential within these areas of research. Investigators of viral oncology are also finding this animal to be of increasing value. The owl monkey holds special importance in vision research because of its unique eye structure.

\section{Foreign Sources}

This monkey is widely distributed throughout Central and South America. The northern Colombian subspecies of owl monkeys, urgently needed for human malaria research, have been very difficult to obtain because of dwindling populations resulting from habitat destruction. According1y, the Colombian government, as well as other source countries, has tightened control over the trapping and exportation of this and other subspecies. Small numbers of Aotus are still available through normal commercial channels although the magnitude and predictability of supplies remain uncertain at best.

\section{Production in United States}

There are a few institutional breeding colonies of owl monkeys, but production is extremely small. Experience, to date, in the breeding of this primate is also very limited, and the degree of success correspondingly is poor. The animal is very fragile, and the techniques have not yet been developed for efficient breeding in captivity. of all the breeding performed in the United States, there are no known general-purpose production colonies in operation, so researchers requiring this animal must either procure it from commercial channels or breed the animal themselves.

\section{Recommendations}

Since this animal is available in limited numbers through commercial channels and some additional numbers may be made available through international cooperative programs, major efforts to increase domestic production are not warranted. However, since this animal is considered essential for some purposes, an effort to increase our ability to breed it in captivity is necessary, in case it is unavailable from the wild. It is, therefore, recommended that a general-purpose production colony be established which would be capable of producing at least 150 animals per year. This animal should then be made available to the research community in general for appropriate study. The northern Colombia subspecies should be given preference when establishing this colony. 
Pan troglodytes (Common Chimpanzee)

Utilization

The chimpanzee is the irreplaceable model for study of certain human health problems. The alternative subject for such studies is man himself, and research with human beings is less feasible than ever. The chimpanzee is in great demand for research in hepatitis, especially hepatitis $B$ to which it is the only animal other than man known to be susceptible. This ape is also used for studies of various other human diseases and for psychobiological research. In total, approximately 180 chimpanzee are needed each year. As man's surrogate for evaluation of many health hazards and health protective measures, this animal is without equal.

\section{Foreign Sources}

The chimpanzee, which originates from West Africa, is threatened, and international trade is controlled accordingly. Although threatened, it is difficult to protect in some of its remote native localities, where it is considered an agricultural pest and killed. Such animals should be removed for biomedical studies and/or breeding projects, but an adequate arrangement for this remains to be developed.

\section{Production in United States}

Some captive breeding of this threatened species is now underway in the United States, producing about 75 animals annually. These domestically produced chimpanzees are all required for specific high-priority research activities which can justify the $\$ 5,000$ to $\$ 10,000$ cost per animal. A project, initiated in 1977, was designed to acquire chimpanzees for breeding purposes from research projects where they are no longer needed. Progeny of this colony and animals unsuitable for breeding will be made available to the general research community. Approximately 20 animals per year should eventually result from this effort.

\section{Recommendations}

The high cost of the chimpanzee, combined with difficulties in importing new animals for breeding stock have been limiting factors in the development of domestic production. However, because this species is irreplaceable for several specific kinds of research, sponsors should consider the advisability of supporting a nationally coordinated chimpanzee production program to meet their overall needs on a continuing basis.

It is recommended that efforts on an international level be undertaken by the IPSC to arrange for the recovery of chimpanzees that might otherwise be killed as pests and to investigate the possibility of establishing formal arrangements to breed this animal in captivity within its countries of origin. 
Hylobates spp. (Gibbons)

\section{$\underline{\text { Utilization }}$}

The white-handed gibbon has been identified as a model for study of certain cancer viruses. Recent work suggests that gibbons may be of value for hepatitis B research; they are also used for behavioral studies.

\section{Foreign Sources}

The gibbon is found throughout most of southeastern Asia, including nearby islands of Indonesia. Since this animal is confined to areas of primary forest, clear-cutting lumbering practices and general deforestation have caused gibbon population reductions in some localities. In recogniton of this situation, this animal has been identified as endangered, and steps have been taken to control its international trade.

\section{Production in United States}

The limited breeding of gibbons has been designed to fulfill specific research needs within a few institutions. No known production exists from which this animal is made available to the general biomedical community. Captive breeding of this animal is expected to be extremely costly, approaching that of the chimpanzee, at $\$ 5,000$ per yearling animal. This, combined with the difficulty in obtaining gibbons, may contribute to the lack of additional interest in domestic production.

\section{Recommendations}

The demand for the gibbon as a model for certain cancer-virus research has increased as has cancer research in general. The estimated requirement of 100 animals in 1977, a rather small numerical requirement, reflects the difficulty of obtaining the gibbon rather than the full extent of the need. It is, therefore, recommended that the IPSC investigate the possibility of establishing cooperative breeding/conservation programs within interested source countries in order to ensure additional supplies of this animal. Since available breeding stock is limited at this time, they should be reserved for the special breeding programs for cancer research. If breeding animals become available, consideration should be given to the establishment of a general-purpose production colony. 
Papio spp. (Baboons)

Utilization

The baboon is a large, hardy primate. It is especially desirable for surgery, neurophysiology, and reproductive physiology research. It is considered a general-purpose primate, and approximately 1,200 are used in the United States each year.

\section{Foreign Sources}

The baboon is found over a very wide range of Africa, south of the Sahara. It remains relatively abundant, but in many areas it is being exterminated because of crop damage. It is probable that supplies of wild-caught animals will continue to be available via existing trade channels for the next few years.

Production in United States

Currently, there are special domestic breeding colonies producing animals primarily for the study of reproductive physiology requiring the use of timed-pregnant animals, neonates or other fetal material. Although the use of the baboon is fairly widespread, general-purpose production colonies have not been established because of the relative abundance of the baboon in the wild, or because special research needs require special production techniques.

Recommendations

The development of general-purpose production colonies on a national scale is not necessary at this time because of the factors mentioned above. However, all sponsors are urged to review their specific needs and establish breeding programs to meet those needs where appropriate. The use of the baboon should be continually reassessed by the IPSC to determine if production colonies should be recommended. 
Cercopithecus aethiops (African Green Monkey)

Utilization

Approximately 2,100 African green monkeys are used each year within the United States, primarily for the production of biological material and toxicology testing. Tissue cultures made from the kidneys of this animal are essential for the production of SV40 virus-free poliomyelitis vaccine. The National Heart, Lung, and Blood Institute is also developing this monkey as a model for the study of hypertension. The use of this animal for other biomedical purposes has been somewhat inhibited because of its association with a severe and fatal disease that occurred among laboratory workers in Marburg, Germany, who had contact with newly imported members of this species.

\section{Foreign Sources}

The African green monkey is widely distributed throughout the African rain forest, woodland, and savannah. This animal has been readily available from normal commercial channels. Potential policy changes, including conservation measures in source countries, make the future availability of this species uncertain.

Production in United States

Limited special-purpose production of the African green monkey is carried out within several institutions for their own use. General-purpose production has not been necessary because of the ease of acquiring this animal from commercial importers as well as the favorable cost.

\section{$\underline{\text { Recommendations }}$}

Because of the demonstrated need for this animal in the production of biologics and other products essential to the health and well-being of the country, it is necessary to ensure that a domestic-production capability exists which can be relied upon if foreign sources of supply are eliminated. It is, therefore, recommended that this breeding capability be established within the United States. To provide the protection afforded by redundancy, two colonies should be established with an expected annual production of 100 animals each. 
Saimiri sciureus (Squirrel Monkey)

\section{Utilization}

The squirrel monkey is the second most widely used primate by the worldwide biomedical community. The numbers required within the United States rank third after the Macaca mulatta and the M. fascicularis. The estimated 4,500 required each year are used for a wide variety of health research and testing purposes, including the major areas of nutrition and cardiovascular research, and studies concerning neurophysiology, pharmacology, and toxicology, to name just a few. The squirrel monkey is considered to be a general-purpose experimental primate.

\section{Foreign Sources}

Although the squirrel monkey is widely distributed in significant numbers throughout northern South America and Central America, each geographical group has differing population levels. Those found in the regions near Leticia in Colombia and Iquitos in Peru, traditionally used for biomedical purposes because of the extensive baseline of data which defines these animals, are in most demand but, unfortunately, are no longer available through commercial channels.

It is, however, expected that this animal may be available in limited numbers from these regions as a result of the PAHO primate production program. The squirrel monkey from other areas is currently available commercially.

Production in United States

Three general-purpose production colonies of squirrel monkeys are supported by the Public Health Service. These colonies are expected to produce 750 to 800 animals each year.

Recommendations

Current supply sources for the squirrel monkey appear to be adequate. Animals are available from commercial sources as well as from domestic breeding colonies. Additional animals are also expected to become available through the PAHO primate production program. Therefore, supplementing our domestic production capacity is not warranted at this time, although the situation should be continually reevaluated and appropriate action taken as the circumstances may dictate.

Efforts should also be made to obtain baseline data for many of the more widely distributed geographic groups to determine if they might be as desirable as those currently used for research models. Increasing the utility of this animal is in concert with general conservation principles since our demand for a few threatened geographical groups is thereby reduced. 


\section{Utilization}

Numerous other kinds of primates are used in biomedical research, the most important being patas monkeys (Erythrocebus patas), spider monkeys (Ateles spp.), capuchins (Cebus spp.), tree shrews (Tupaia spp.), and bushbabies (Galago spp.). Each of these species is used in relatively small numbers for special purposes in a wide variety of institutions. To date, none of the species has been identified by the biomedical community as having the same degree of importance as the previously discussed species.

\section{Foreign Sources}

The New World species (spider monkeys and capuchins) are difficult to obtain commercially; the other named species are currently obtainable in the numbers desired. The availability of species not discussed here varies according to the species in question. A general statement can, however, be offered: The Convention on International Trade in Endangered Species has specified that all primate trade should be controlled since continued availability of nonhuman primates in general is by no means certain and for some species is most likely extremely limited.

\section{Production in United States}

Any domestic breeding of these animals is done on a very small scale to fulfill special needs by individual institutions. The level of requirements for these animals has not been sufficient to support general-purpose production.

\section{$\underline{\text { Recommendations }}$}

Since the availability of these animals in the future is, at best, uncertian, sponsors are urged to evaluate their long-term needs and develop domestic production colonies where indicated. The IPSC should keep abreast of this activity and continually reassess national requirements for these primates to determine if general-purpose production is necessary. 
APPENDIX C

INTERAGENCY PRIMATE STEERING COMMITTEE

MEMBERSHIP 


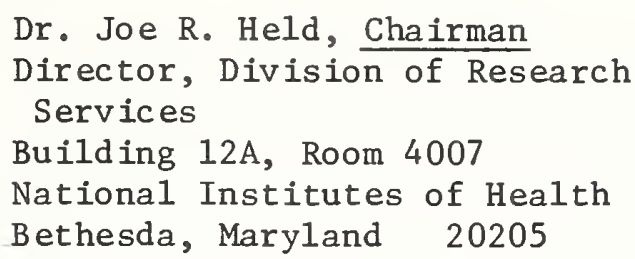

Dr. Thomas G. Bowery

Director

Division of Research Resources

National Institutes of Health

Bethesda, Maryland 20205

Colonel Francis C. Cadigan

Director of Biomedical Laboratory

Aberdeen Proving Ground

Aberdeen, Maryland 21010

Dr. Jules Cass

Chief Veterinary Medical Officer

Medica1 Research Services

Veterans Administration

810 Vermont Avenue, N.W.

Washington, D.C. 20420

Mr. Kurt Habel

Office of Program Planning

and Evaluation

National Institutes of Health

Bethesda, Maryland 20205

Dr. Robert de Caires

Director

Division of Program Analysis

Office of International Health

Parklawn Building, Room 18-87

5600 Fishers Lane

Rockville, Maryland 20852
Mr. George E. Renaud

Chief, Experimental Psychology Section

National Institute of Mental Health Rockville, Maryland 20852

Dr. Fred Stollnitz

Program Director for Psychobiology

National Science Foundation

Washington, D.C. 20550

Dr. Johannes Stuart

Associate Director

Center for Disease Control

Parklawn Building, Room 17B19

Rockville, Maryland 20852

Dr. Frode Ulvedal

Supervisory Toxicologist

Environmental Protection Agency

Health Effects Division

401 M Street, S.W.

Washington, D.C. 20460

Dr. James H. Vickers

Director, Pathobiology \&

Primatology Branch

Division of Pathobiology

Bureau of Biologics, FDA

Building 29, Room 510 (NIH)

Bethesda, Maryland 20205

Dr. Benjamin D. Blood

Executive Director

Interagency Primate Steering

Committee

NIH Building 31, Room 4B30

Bethesda, Maryland 20205 
APPENDIX D

U.S. DOMESTIC PRODUCTION OF NONHUMAN PRIMATES

SUPPORTED BY FEDERAL GOVERNMENT 


\section{,}


Table 11

U.S. Domestic Production of Nonhuman Primates Supported by Federal Government by Sponsor and Species

\section{Projected Levels*}

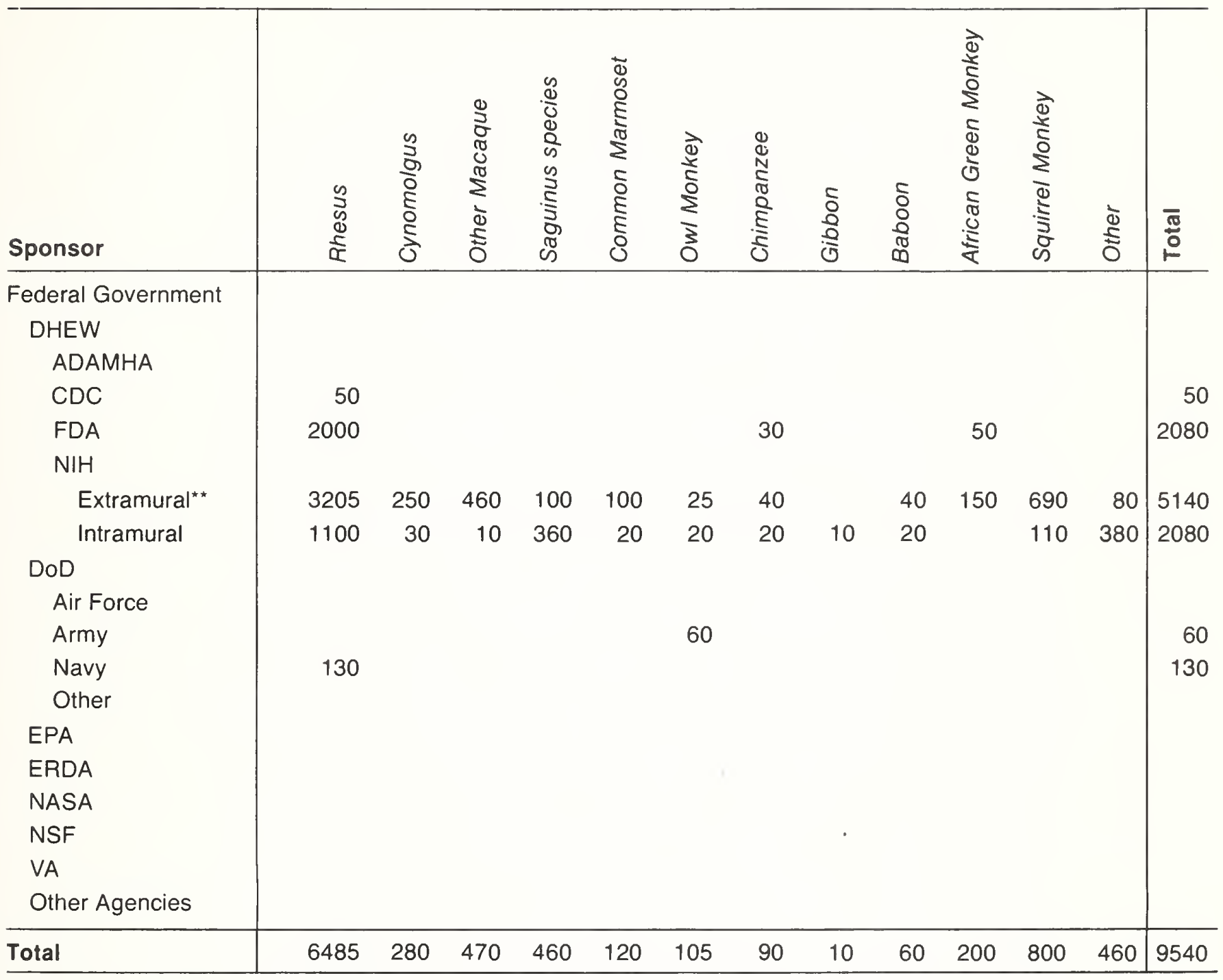

*Table includes special-purpose breeding colonies designed to produce animals with unique characteriestics for use in individual projects.

" "Supplies ADAMHA with approximately 100 rhesus monkeys per year. 
APPENDIX E

SUMMARY OF

INTERAGENCY PRIMATE STEERING COMMITTEE

RESPONSIBILITIES 
The Interagency Primate Steering Committee (IPSC) was established to develop a unified approach to assure both short- and long-term supplies of nonhuman primates for national health needs. The National Primate Plan, developed as this unified approach, recognizes the continual need for a coordinated program and recommends that the IPSC continue to perform in this capacity. Specific responsibilities, consistent with the initial charge made to the IPSC, are identified within the National Primate Plan and are summarized below.

Responsibilities for Ensuring the Most Effective Use of Primates

* Programs developed by sponsors to ensure the effective use of primates will be reviewed by the IPSC to determine the completeness of the programs and their adherence to established criteria. The IPSC will also be available to sponsors for advice and assistance during the development of these programs.

* The IPSC will serve as the channel for determination of impact of any regulation, standard, or guideline developed by Federal agencies which either requires that primates be used or restricts their availability. The IPSC will also be available for advice and assistance to these agencies in the early stages of the regulatory development process.

Responsibilities for the Production of Primates in the United States

* The IPSC will plan and coordinate a national program of domestic primate production. The funding and operation of specific primate production programs, however, remains a responsibility of sponsors. The IPSC, from its supervisory perspective of the overall primate usage and supply system, will recommend specific courses of action for the consideration of these sponsors to ensure the development of a balanced, comprehensive program of domestic primate production.

* The IPSC will review proposals developed by sponsors for the production of primates and will facilitate the exchange of information between sponsors of such programs. This service will be available to all sponsors, including those of the private sector.

Responsibilities for Ensuring a Stable Supply of Primates From Foreign Sources

* In response to the overall needs of sponsors and performers, the IPSC will develop international cooperative programs to ensure a 
stable supply of primates from foreign sources. Accordingly, the IPSC on its own initiative will undertake specific action, consistent with the objectives, guidance, and policy presented within the national plan, in the development of such programs. Once established, those projects which result in the creation of operational supply programs become the responsibility of the sponsor receiving the greatest benefit from the program.

* The IPSC will coordinate all negotiations and conduct of international programs undertaken by United States sponsors which are designed to assure adequate supplies of primates from foreign sources.

\section{Responsibilities for Allocating Primates}

* Although the allocation of primates is the responsibility of sponsors, the services of the IPSC are available to assist in this process when desired.

* In the event supplies of one or more species of primates are insufficient to meet critical health needs, the IPSC will facilitate interagency consultations regarding allocation and will provide an opportunity for the participation of nongovernmental institutions requiring primates.

* In emergency situations or in the event interagency consultations do not produce agreement, the IPSC will present the matter with recommendations to the Assistant Secretary for Health, DHEW.

Responsibilities for Information Collection, Analysis, and Dissemination

The design of future programs and actions is primarily dependent upon accurate and comprehensive information. The IPSC will provide information and its corresponding analysis to sponsors and performers in four specific areas:

1. the overall need for primates;

2. the availability of primates from foreign sources; 
3. the current and planned domestic capability of primate production; and

4. a continuing analysis of factors that may have impact on the overall primate usage and supply system in both short and long terms.

While the responsibility for collecting detailed data specific to an individual sponsor rests with the sponsor, the IPSC will collect data summarized by sponsors and develop an overall picture of the nation's requirements for primates and the availability of primates to meet those requirements.

Based on an understanding of the total primate usage and supply system, the IPSC will advise and coordinate the activities of sponsors and performers in their efforts to meet those national health needs requiring the use of primates. Other specific responsibilities, identified within the National Primate Plan, logically fall to the IPSC as a result of this understanding. 

DISCRIMINATION PROHIBITED: Under provisions of applicable public laws enacted by Congress since 1964, no person in the United States shall, on the ground of race, color, national origin, sex, or handicap, be excluded from participation in, be denied the benefits of, or be subjected to discrimination under any program or activity receiving Federal financial assistance. In addition, Executive Order 11141 prohibits discrimination on the basis of age by contractors and subcontractors in the performance of Federal contracts. Therefore, the National Primate Plan must be operated in compliance with these laws and executive order. 
U.S. DEPARTMENT

OF HEALTH, EDUCATION, AND WELFARE

Public Health Service

DHEW Publication No. (NIH) 80-1520

National Institutes of Health 